\title{
How Inclusion can Exclude: The Case of Public Toilet Provision for Women
}

\author{
GAIL RAMSTER, CLARA GREED and JO-ANNE BICHARD
}

\begin{abstract}
Our built environment is required to meet human needs at the most basic of levels. If our pavements and roads afford our movement across the built environment's landscapes, then provisions should also be in place to meet the needs of the body in motion. This paper will take a historical perspective of the introduction and design of public toilets to illustrate how certain spaces in the city were defined by the bodies that toilet provision served. It will show how biological functions such as menstruation are not being met by public toilet design and infrastructure, and how overall provision is inadequate for women for both biological and social factors. Public toilets reflect and reinforce a binary gender society, resulting in some users being excluded or their rights to access challenged by others. A new chapter is currently being written regarding the needs of transgender people, raising questions around existing design differences between men's and women's toilets and the very notion of segregating public toilets by gender, evident through the growing numbers of 'gender-neutral toilets'. However, these changes to public toilet design and provision are emerging without expert guidance and with a lack of research into how this might positively or negatively impact different groups. Designers, architects and planners are facing a series of interesting challenges when considering how new and existing UK provision can be inclusive of a diversity of bodies and their rights to access without excluding those socially and culturally dependant on a gender-segregated space.
\end{abstract}

Public toilets are in the news again. This news cycle does not involve the vandalism, closure, a person taken ill (which can be a euphemism for a drug overdose), or misconduct (such as sexual liaison) that fill the pages of local papers on a weekly basis. Public toilets providers have begun to experiment with the very organizing structure of how many people decide which toilet to use. In October 2016 the Barbican complex in London made a set of toilets outside one of its cinemas gender-neutral. The re-designation was not through a major refurbishment or redesign, instead the sign that had previously identified provision as male and female was replaced with 'gender-neutral with urinals' and 'gender-neutral with cubicles'. This resulted in a flush of news reports that incorporated the usual puns, both local and national. The Islington Tribune announced: 'We won't stand for gender-neutral loos say women' (Couvée, 2017) while the Daily Mail exclaimed 'Loo must be joking!' (Sinmaz and Strick, 2017). Not all reports were aghast at this challenge to conventional norms. Radhika Sanghani in the Daily Telegraph put forward the case for 'Why the UK should ditch male and female toilets for "gender-neutral" loos' by highlighting the challenges and in some cases violence and intimidation faced by transgender people (Sanghani, 2017). In the Guardian, philosophers Luc Bovens and Alexandru Marcoci 
from the London School of Economics described how their research into the economics of toilet provision suggested that gender-neutral facilities would cut down waiting times for women, while also addressing wider community concerns (Bovens and Marcoci, 2017). Journalist and transgender rights activist Paris Lees succinctly captured the central point of the Barbican 'toiletgate' by pointing out that much of the built environment's provision is already gender-neutral, and that while 'a perfectly sensible idea' the way the provision had been introduced left much to be desired (Lees, 2017). Inclusive toilet provision requires more design and planning consideration than merely replacing signs on doors. As Penner (2001) notes:

... a lavatory is not simply a technological response to a physical need but a cultural product shaped by complex and often competing discourses on the body, sexuality, morality and hygiene. (Ibid., p. 26)

\section{A Tale of Two Toilets}

The history of public toilet provision can help illustrate how changes in toilet access are so emotive, and can find people avoiding places and businesses that do not provide toilets that meet their needs (Greed, 2003; Hanson et al., 2007; Bichard, 2015).

Public toilets are traditionally viewed as sanitation facilities provided by local authorities. As provision has fragmented (Greed, 2003; 2009) between the public (local authorities) and private providers (train stations, cafes, department stores, supermarkets, shopping centres, service stations etc.), provision has come to be known as 'publicly accessible toilets' (Knight and Bichard, 2011).

Powers for local authorities to provide public toilets at their discretion were first introduced under the 1848 Public Health Act (Greed, 2003). This introduced a range of measures to improve sanitation, drainage and sewerage. In the UK, many of the public toilets built in the Victorian era, were placed underground replacing existing urinals (McCabe, 2012), in close proximity to the main sewers and were often spacious and well maintained. However, the resilience of these facilities within the built environment did not consider wider population requirements. The need to descend and ascend multiple steps made this provision difficult to access, especially for some ageing and/or disabled people or those, predominantly women, caring for babies and young children (Bichard et al., 2004).

The history of provision reveals that initially toilets were not 'public', but more 'publicly accessible'. The first major provision in the Crystal Palace at the 1851 Great Exhibition held in Hyde Park showcased 'halting stations' designed by George Jennings. Available for men and women and charging a penny per person, these netted Jennings a profit of $£ 2,441$ (McCabe, 2012), and coined the lasting phrase 'to spend a penny'.

The success of Jennings 'halting stations' would result in his persuading the City of London to install more public conveniences and the world's first underground provision was opened in 1855 . However, it would only cater for men and it would be almost 40 years before women in the capital would have public toilet provision (Ibid.). Prior to this onset of civic sanitation awareness, there were many urinals dotted around the city, as well as the provision in public houses, traditionally a rest stop with general access to toilets but only for men. Thus the Victorian city, by offering single-gendered toilet provision would become a gendered space.

This spatial division was also reflected in professions where most of the engineers, architects and decision-makers in this era (and into the present) were also male, and due to wider social propriety, women's needs were not discussed or considered. The legacy of Victorian provision has echoed beyond professional gender roles. McCabe's analysis of the design of underground public toilets shows that the division of provision was biased towards men. Citing facilities at Holborn, McCabe shows how male provision equated to twelve urinals and eight cubicles, 


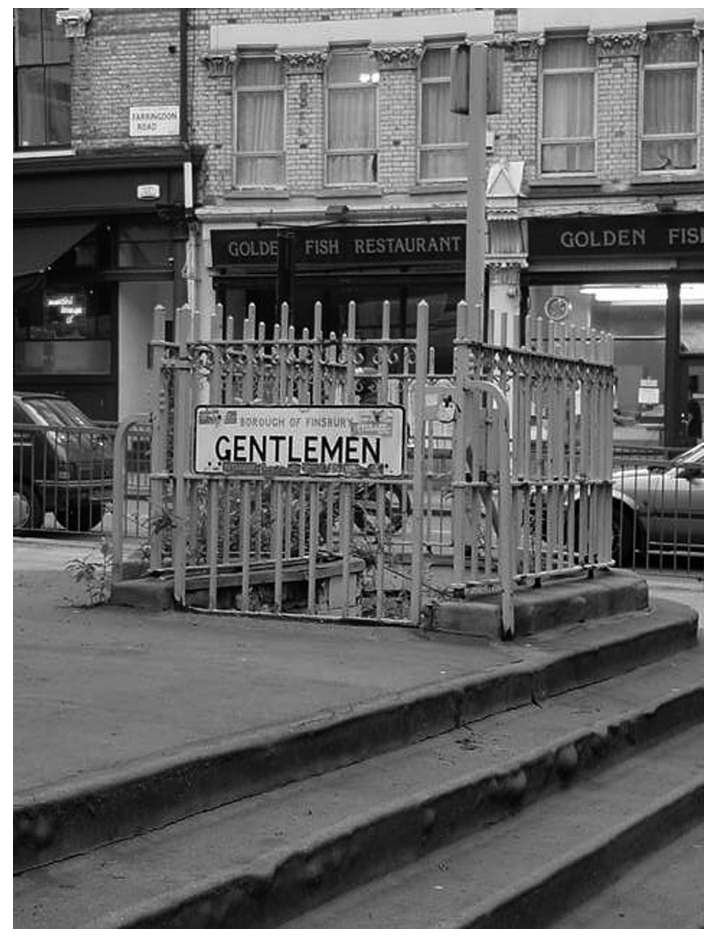

Figure 1. Gentleman's Victorian subterranean toilet in Clerkenwell, London. (Source: Bichard, 2004)

whereas the women's toilets consisted of six cubicles 'meaning the aggregate provision for men is over three times that of women' (Ibid., p. 48). Yet McCabe also describes that the workforce of the time consisted of 20 per cent women, thus it may be considered that the third of provision for a fifth of the workforce could be a sign of a time of progressive design.

However, such division in provision is not suitable for a twenty-first century state where women are now the majority of the population (ONS, 2016), of which nearly 71 per cent are in employment (ONS, 2018) and make up 46 per cent of the workforce (Catalyst, 2016).

The Public Health Act would be consolidated in 1875 , to bring together sewage and wider sanitation concerns. It would then not be revisited until 1936 when the Act permitted local authorities to build public toilets if they

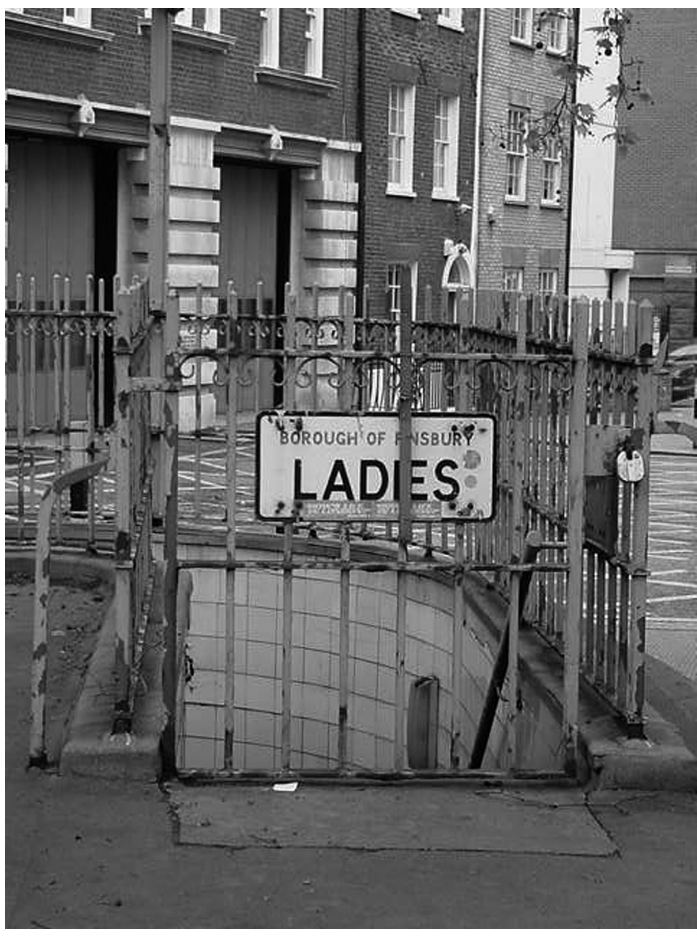

Figure 2. Ladies Victorian subterranean toilet in Clerkenwell, London. (Source: Bichard, 2004)

wished, but placed no requirement on them or any other government body to do so. While discretionary and not obligatory, it did make the principle of public toilet provision acceptable and, more importantly, financially supported as part of a wider programme of public health, and public toilets would come to reflect civic pride. Yet the 1936 Act also represented the gender biases of the time by enforcing inequality between the way genders could access public toilets. Under Section 87 sub-section 3, local authorities were empowered to charge such fees as they think fit 'other for urinals' resulting in men being able to urinate for free while women had to pay (Public Health Act 1936 s87(3)(c)). This inequality continued until 2008 when the Public Health Act was amended under sex discrimination law to remove the exemption (The Sex Discrimination (Amendment of Legislation) Regulations 2008 (No.963)). 
Charging for toilets was achieved through the 'penny in the slot' door lock, to be replaced when turnstiles were installed at the entrance. The 1965 Turnstiles Removal Act saw these barriers removed, and many local authority public toilets were made free. Private provision such as toilets in railway stations was exempt from the act and hence turnstiles remained. The ban on turnstiles was lifted in the London Local Authorities Act 2012. This, along with the removal of the 'free to pee' exemption for urinals, has made it easier to charge both genders (anything up to 50 pence). By their very nature, turnstiles defy an inclusive approach to access, and restrict people with pushchairs and those who use wheelchairs. In many cases people who are larger find them difficult to negotiate, older people with less momentum and strength to 'push' the turnstile and anyone using any form of walking aid may also find them difficult, and of course those who cannot afford the entrance fee are excluded (Greed, 2003; Bichard, 2015).

Toilet provision in London that was designated for 'men only' existed well into the 1980s. Islington Council documents reveal that at the beginning of the 1980 s the borough

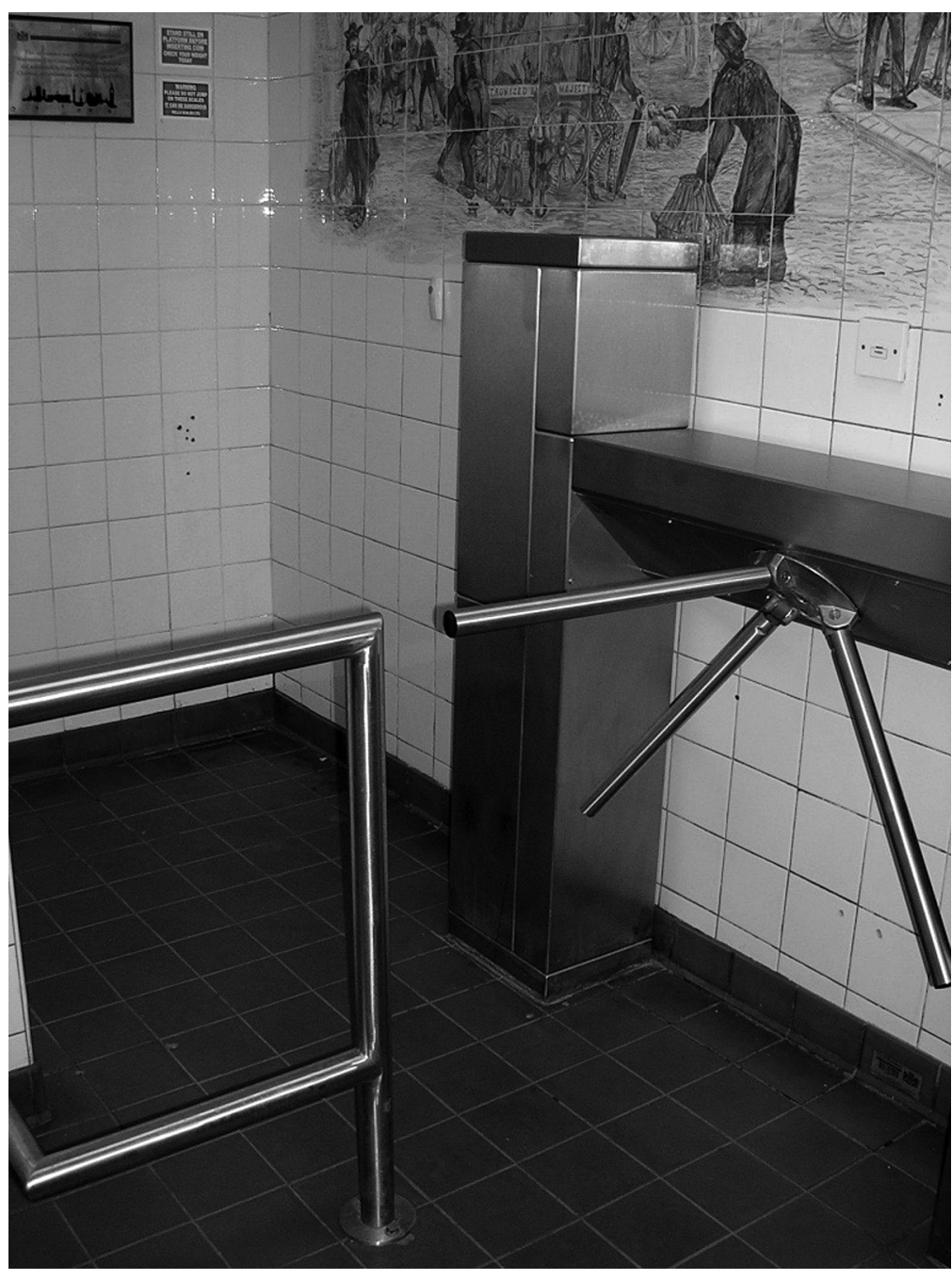

Figure 3. Turnstiles have returned to many public toilets, Westminster, London. (Source: Bichard, 2005) 
had twenty public toilets and six urinal facilities. Of these twenty facilities fourteen had accessible provision and four of the toilets were exclusively for men (Bichard, 2010).

Throughout these changes a clear constant has remained that toilet provision be divided by male and female although the parity of provision has remained far from equal (with urinals and cubicles, men often continue to have more provision than women). This gender segregation continued until the 1970s when a third option was offered in the form of the unisex accessible cubicle. A 1961 survey of London's toilets had revealed that 60 per cent were subterranean Victorian facilities (Don, 1961) and therefore difficult or impossible to access for people who had mobility impairments. The need for public toilet pro- vision as the highest priority for disabled people was identified through interviews with 284 disabled people by architect Selwyn Goldsmith, author of Designing for the Disabled (1963). The first unisex accessible toilet would be built in Norwich in 1964, and by 1970, the Chronically Sick and Disabled Persons Act would see buildings open to the public required to have accessible toilet provision. A key element of the accessible unisex provision was that people of opposite genders could access the toilet together. This ensured people could be assisted by their relatives or carers, and would become the footprint for a number of gender-neutral toilet designs including the universal accessible cubicle (that included both standing and sitting wash basins), the Changing Places cubicle (for

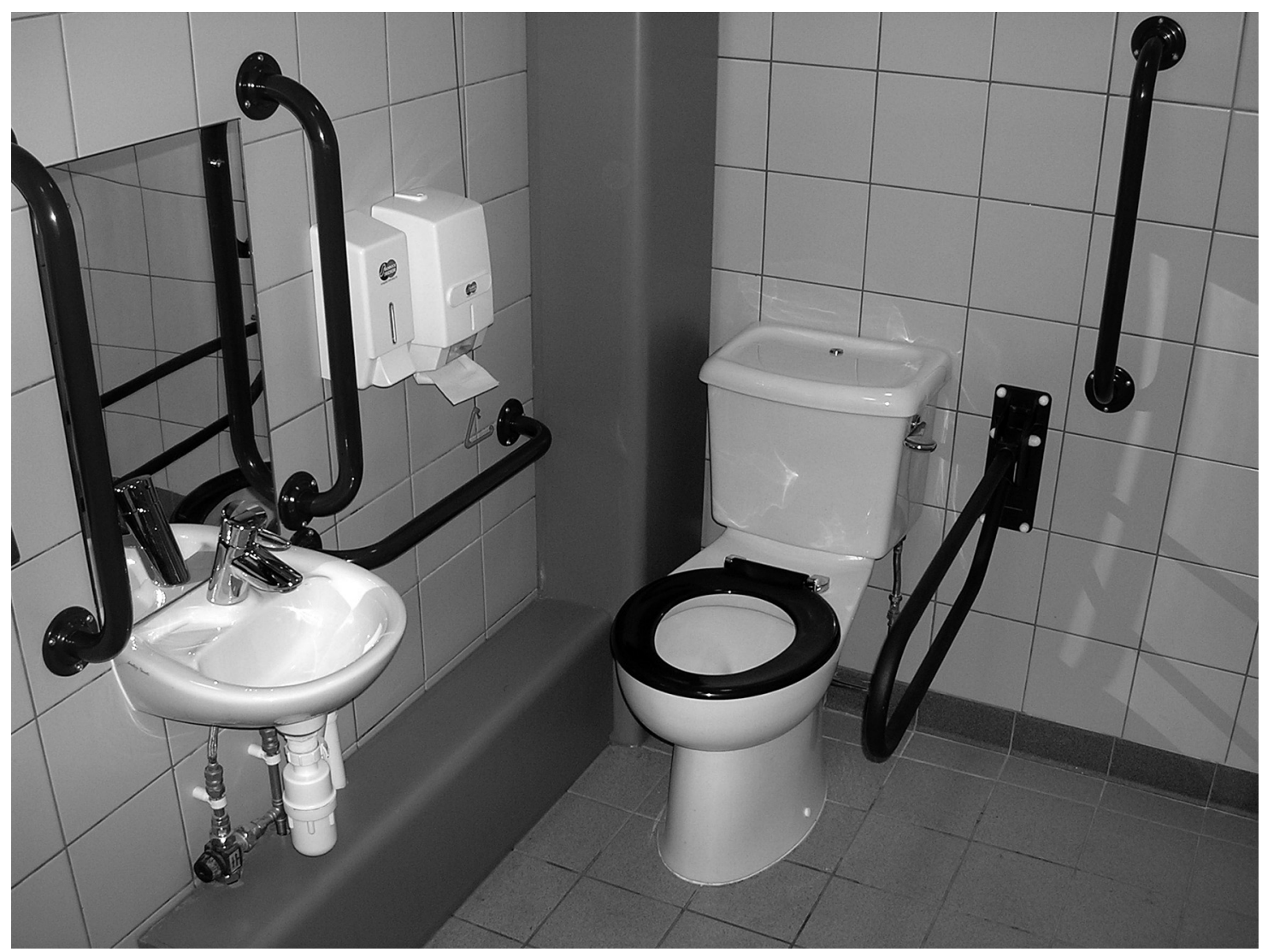

Figure 4. The unisex accessible cubicle (note alarm is incorrectly installed). (Source: Bichard, 2006) 
people with profound and multiple learning disabilities or complex physical disabilities) and family toilets (for parents and guardians accompanied by babies and young children).

By the 'age of austerity' it had been noted that extensive cuts in government funding to local authorities had forced the closure of many public toilets (Street-Porter, 2016), the numbers of which were already dwindling (CLG Select Committee, 2008). The reduction between 2000 and 2016 has been found to be as much as 28 per cent (Knight, 2016), while an investigation carried out by the
BBC found 1,782 public toilets (operated by local authorities) had closed in the previous decade (BBC News, 2016).

The lack of provision and the growth of cafe culture and mega bars resulted in a dramatic increase of street urination, with The National Gallery reporting that uric acid was staining the exterior of the building (BBC News, 2002). This led to the installation of a number of portable and more permanent urinals at various points across central areas of UK cities, at considerable cost.

Yet this provision was once again for 'men

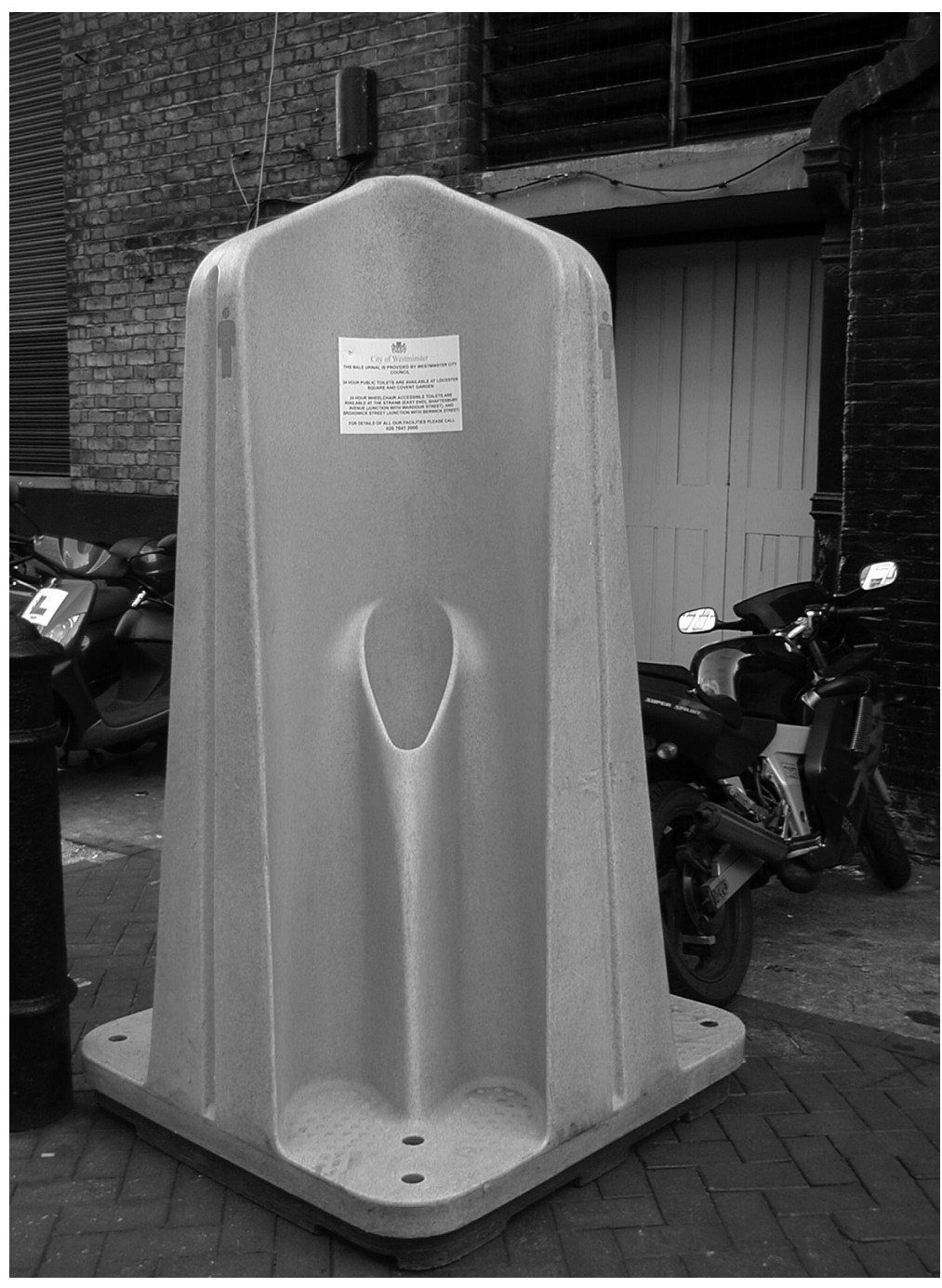

Figure 5. Temporary urinals can be moved to 'wet spot' areas as identified sites of frequent male street urination. (Source: Bichard, 2003) 
Figure 6. Permanent retractable urinal that comes up at dusk and goes down at dawn. (Source: Bichard, 2005)

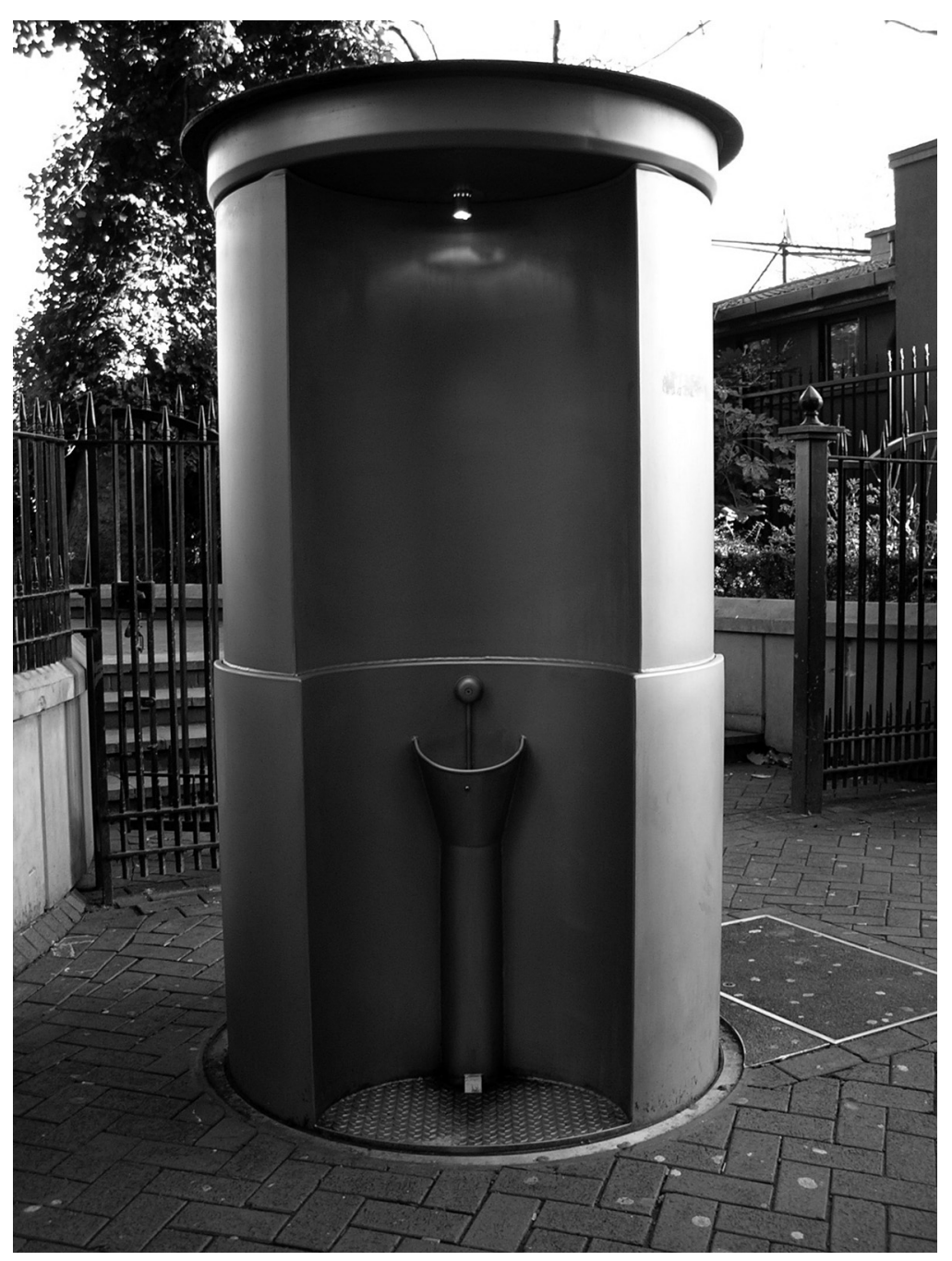

only', and only for men physically and socially able to urinate at an open on-street urinal. Some, such as older men and those who follow faith considerations when toileting would not use the urinals (Hanson et al., 2007). Such provision reflected the Victorian male-dominated city, and a specific male that could afford increased alcohol prices in city centres and who, when under the influence of alcohol, has less concern about urinating in public - albeit in a designated space. As of 2014, such pop-up provision for urination has also appeared for female-sexed bodies (in the Netherlands), yet such innovation ignores that these users have one more bodily need from toilet provision beyond excretion and defecation, namely menstruation.

\section{Blood Ties}

It is widely accepted amongst academics who study toilet design that women are particularly excluded when toilet provision is non-equitable, and that this has been a historical trend (Cavanagh and Ware,1990; Greed, 2003, 2012, 2016; Penner, 2001, 2005, 2013; Gershenson and Penner, 2009). It can be argued that the biological, social and cultural 


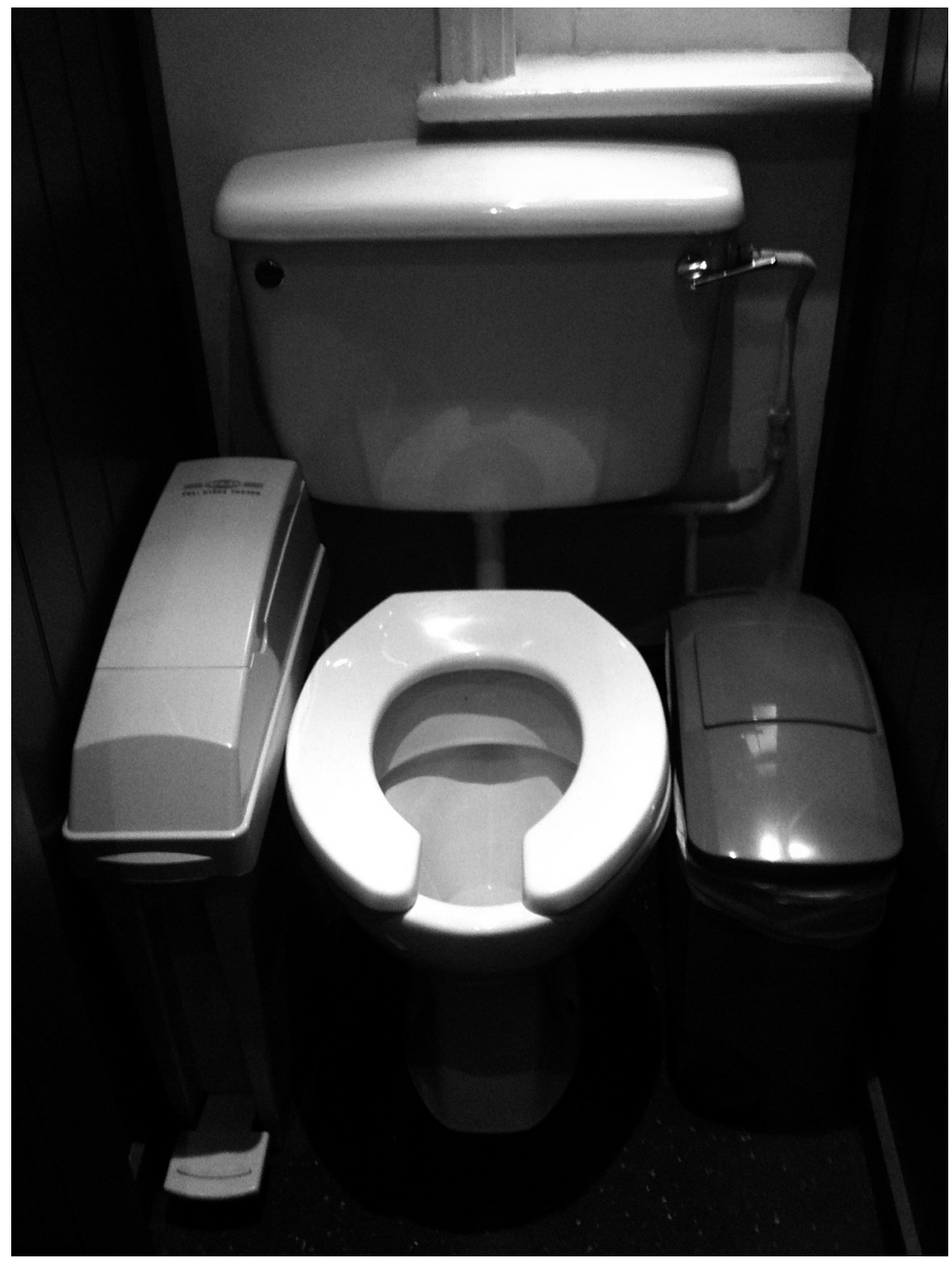

Figure 7. Multiple sanitary bins in standard cubicle illustrate the failure of the infrastructure to consider menstruation. In addition, a lack of consideration in the servicing of bins presents a further compromise of space. (Source: Bichard, 2011) factors that influence women's need for toilets and the time they spend toileting have been counted against them resulting in a historical gendered legacy of the built environment; an experience that can be seen to be handed down through generations, namely, the toilet queue.

Gender remains a major determinant of toilet design and culture (Gershenson and Penner, 2009). Poor design inconveniences women at an excretory and menstrual level, from having to queue for access to negotiating narrow poorly designed cubicles. A blatant identifier of such exclusionary design can be found in the British Standards BS6465 Part 2 that has historically and continues to illustrate the space allocation of the 'standard' toilet cubicle as one without a sanitary disposal bin and one with. Such additional furniture within a small space can, along with an industrial toilet roll dispenser, severely restrict space for movement, which can be especially problematic for women who are in the later stages of pregnancy (and often have to use facilities more), larger women, older women and disabled women who do not feel they have legitimate access to the unisex accessible provision (Bichard, 2015). Yet the provision 
of the sanitary bin reflects a larger gendered issue. With women now over half of the population, many will be menstruating. However, the infrastructure of the built environment does not support the disposal of sanitary products. It has to be remembered that it was only in 2016 that the UK committed to removing the VAT from sanitary products, currently still at 5 per cent. (this does not come into effect until 2018) (Periodwatch, 2018). The low priority given to menstruation is reflected in the plastic bin for disposal, an example of an afterthought in the design of toilets. The need to service sanitary bins also frames menstruation as an afterthought - in many cases one that leaves bins overflowing or multiple bins left in situ. A wider acceptance of menstruation as a biological function of the body, along with urination and defecation, would see it supported in the infrastructure, with a fully integrated disposal system.

The lack of access to toilets can increase the chances of streptococcal toxic shock syndrome for women who cannot find somewhere adequate to change tampons (Armstrong and Scott, 1992; Rothburn and Dunnigan, 2014; WEN, 2012). Disposal bins for pads are required by both men and women who experience urinary and faecal incontinence (Hanson et al., 2007) and men with femalesexed bodies may still have periods and need menstrual disposal provision, although many report avoiding using public toilets when menstruating (Chrisler et al., 2016).

Public toilet provision scarcely takes into account women's different requirements that arise from the anatomy of the female-sexed body and from female gender norms. Both contribute to women needing more public toilets than men (Penner, 2013). Users of UK women's toilets include cis-women, transwomen and young children. Almost all users will sit to urinate. This vulnerable position often requires the removal of clothes, which seasonally will require more space (Kira, 1975). In addition, women are more likely to be carrying bags, adding to the space use and sense of vulnerability. Cultural adherence requires that women use the standard toilet cubicle in privacy in which opening and locking a door, placing a bag or bags somewhere secure, undressing (perhaps removing a coat in winter), all add to the time taken to use the cubicle, and this time increases when a women needs to change sanitary products. Menstruation provides another reason for toileting more often.

Women also still take the primarily role for childcare, and despite Cavanagh and Ware's finding that 71 per cent of the women they interviewed 'thought children should have special facilities' (1999, p. 17) there has been very little in the way of general provision that includes smaller WC pans or lower urinals in the women's toilets (although the latter is sometimes found in the men's). The cumulative effect of these biological, social and cultural factors is that women take on average between one and a half and twice as long to use the toilet than men (Kira, 1975; Bailie et al., 2009), and may also need to use the toilets more often because they have more reasons to do so.

\section{Pees and Queues}

This difference in usage time is an even greater contributing factor to queue times when applied to facilities that already have fewer 'places to pee' in the women's than the men's (due to the different amount of floor space required by cubicles and urinals). Toilet queues are often blamed on women, for 'taking too long' or 'not going before you went out' or seen as a joke (Stanwell-Smith, 2010). Yet in reality toilet queues are an inevitable consequence of a lack of consideration for the different needs of women and men when designing facilities (Knight and Bichard, 2011).

Though longer, queues for the women's may not be excessive if the number of new users arriving is fewer than the total capacity of the facility (Van Hautegem and Rogiest, 2017). Using simulations, Hautegem and 


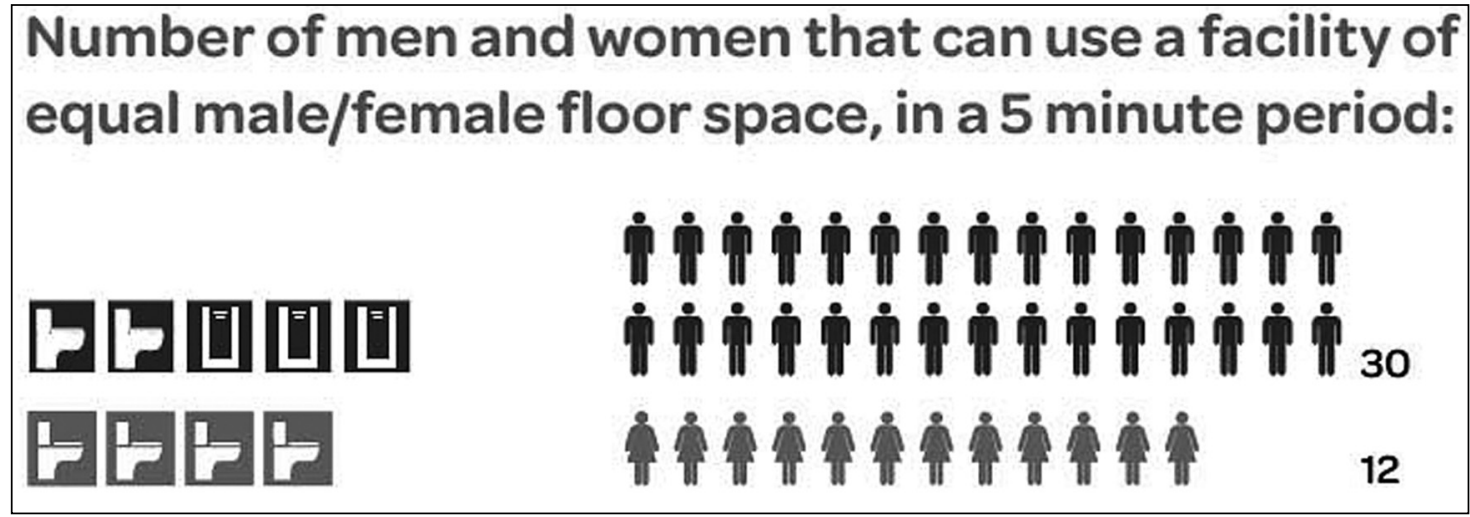

Figure 8. Even providing equal numbers of 'places to pee' does little to redress gender balance in provision, resulting in twice as many male to female users in the same time period. (Source: Knight and Bichard, 2011)

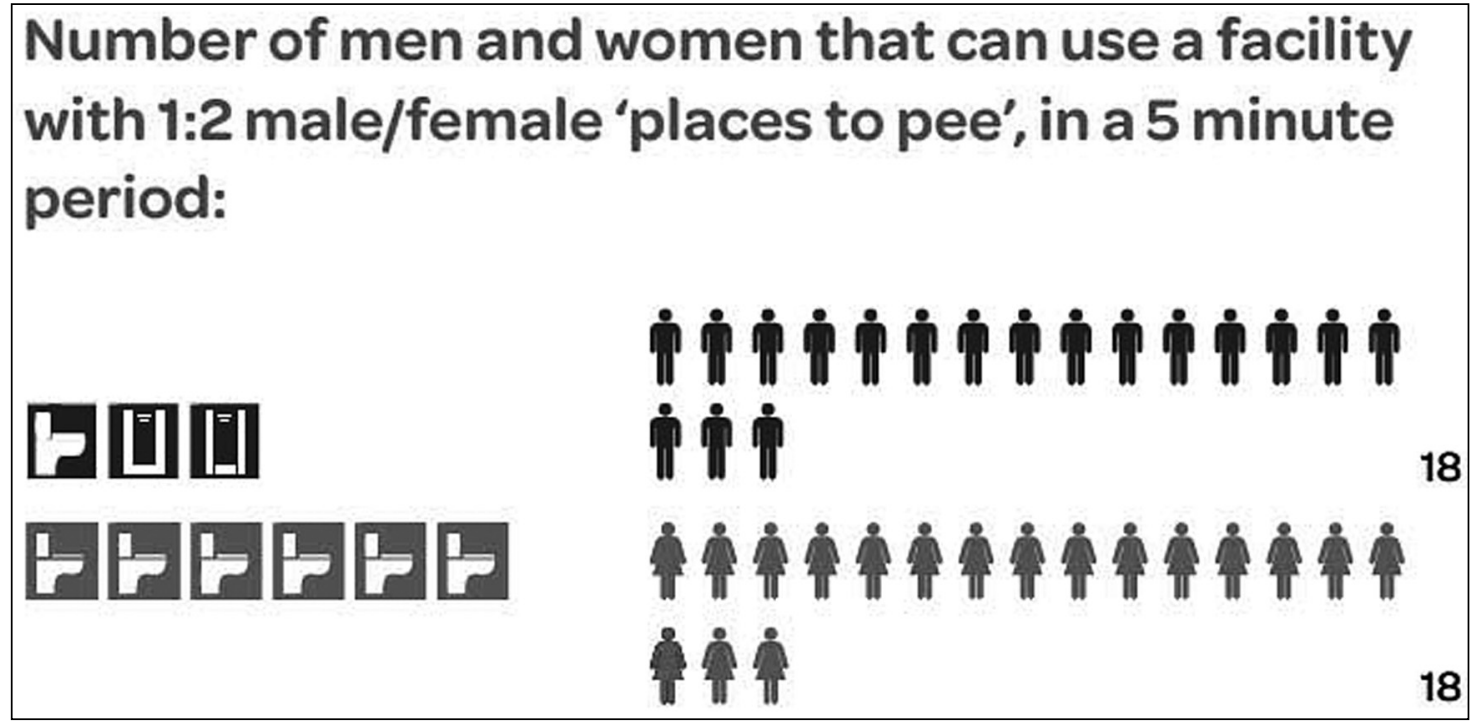

Figure 9. Only when women are provided with twice as many toilets as men do we see equitable provision. (Source: Knight and Bichard, 2011)

Rogiest also mimicked a busy period where the rate at which new people are arriving far exceeds the toilets' capacity. Not only was the women's queue much longer than the men's (11 minutes and 6 minutes 19 seconds respectively) but after the busy period ended the women's queue took 2 hours to return to normal levels; the men's just 15 minutes. This theoretical scenario illustrates how some women's toilets (such as at a shopping centre or train station) might seem to always have a queue even if the building itself does not appear busy.

In the USA women have been campaigning for 'potty parity', not just an 'equal' ratio of 1:1 but 2:1 in favour of women to reduce queues, accepting that women take longer. This has been achieved in over twenty states thanks to the efforts of US women architects and political campaigners (Anthony, 2017, pp. 121-158). There has also been a restroom revolution in Asian territories. The World 
Toilet Organisation and its sister organizations, including the Japan Toilet Association and similar organizations in Taiwan, China and Malaysia, have all taken toilet provision very seriously. Toilet ratios of 2:1, or even 3:1 in favour of women are common in Japan, where the government has invested heavily in toilet provision, and where ideas of civic pride still prevail (Miyanashi, 1996).

The public toilet is regarded as a safe space for women in the male-oriented public sphere. Most designs still include a space shared with and accessed by other women; a space to rest, to talk, to show emotion, to fix one's public appearance (make-up, hair, dress). Women do all this often without entering the cubicle, able to find mental privacy from public space despite still being in the company of strangers, a sanctum away from 'the male gaze' (Mulvey, 1975)

The 'safe space' status might refer more to

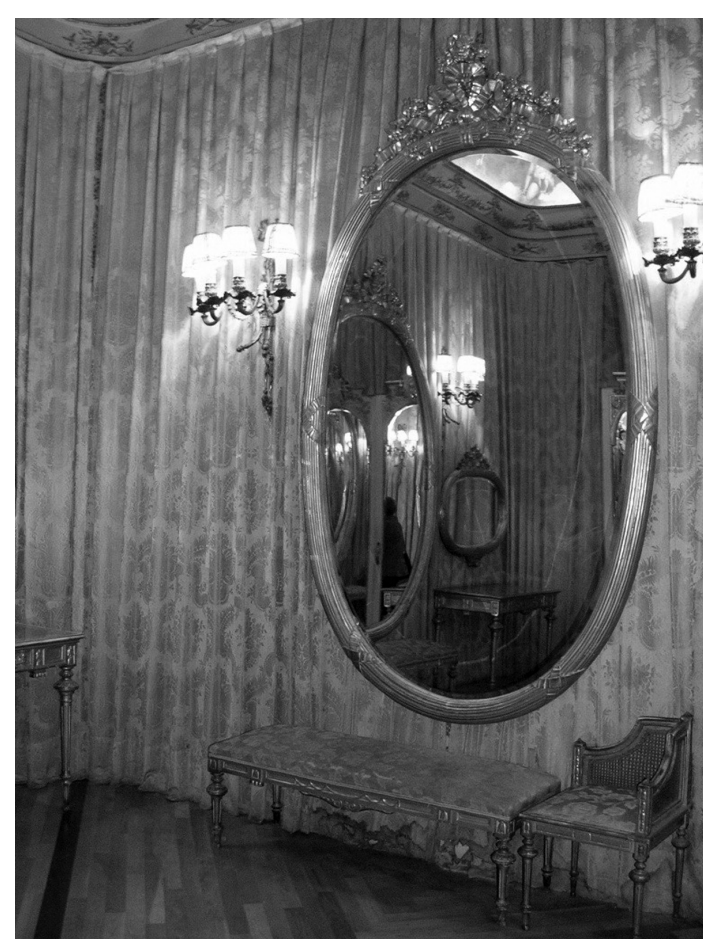

Figure 10. A place to fix one's appearance. Mirrors in women's toilet, Murcia Spain. (Source: Bichard, 2005) the opportunity to perform these acts, as a 'site of female solidarity', than to protection from criminal acts of violence perpetrated by men (Case, 2010). In her US-based research, Case found enough incidents of male-onfemale violence in public toilets to feel that gender-segregation was no protection from this kind of assault, although statistical data on crime were lacking. In the UK, some women's public toilets can also be associated with a lack of safety, yet fear of crime might be created more by vandalism of the facility and other anti-social behaviour than by an actual risk of assault (Cavanagh and Ware, 1990; Knight, 2010). Blocks designed with the intention of giving the user privacy from passers-by can leave users feeling more vulnerable, for example buildings in unsupervised space such as underground or in a park, entered via a self-closing door, screened by foliage and poor external lighting and

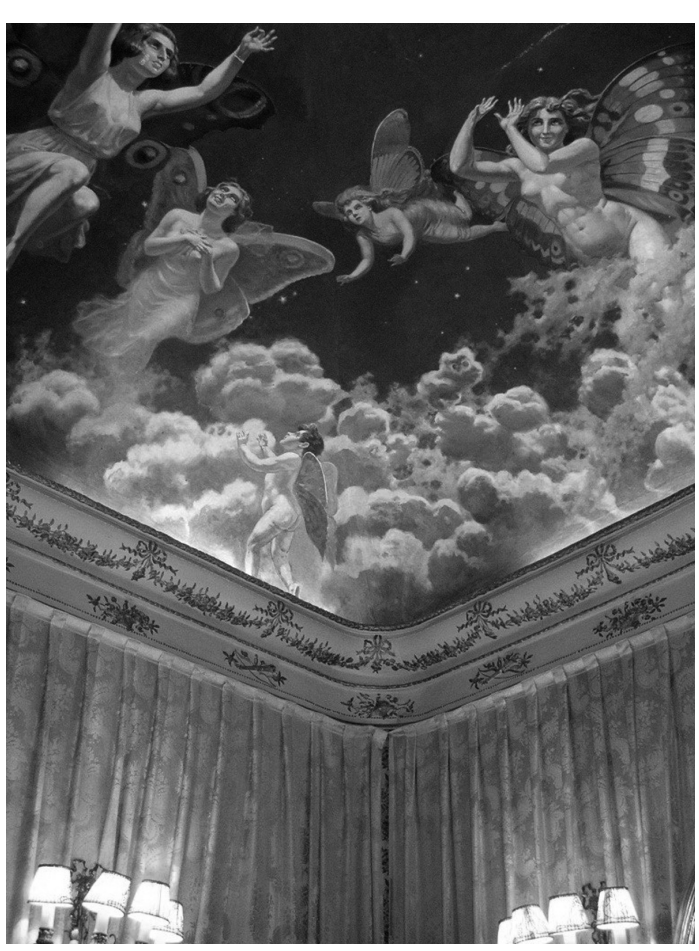

Figure 11. A sanctum from the 'male gaze'. Ceiling decoration in the women's toilet, Murcia, Spain. (Source: Bichard, 2005) 


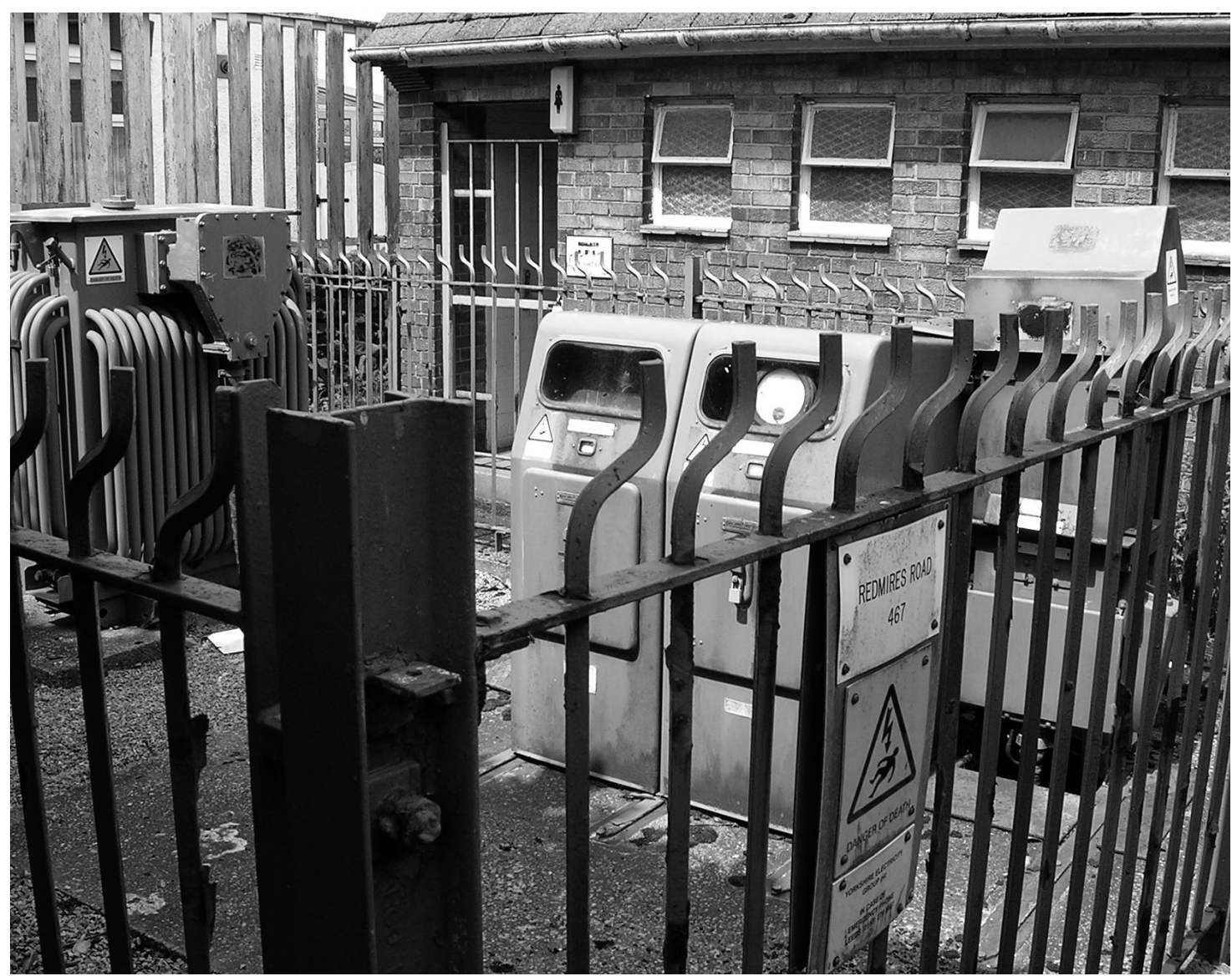

Figure 12. Toilets with poor natural surveillance can be intimidating. This block is located behind an electricity 'sub station'. (Source: Bichard, 2006)

without windows providing natural surveillance from the outside (Cavanagh and Ware, 1990; Greed, 2003).

Design-out crime guidance seeks to remove these elements of public toilet design to address crime and fear of crime for all affected (British Toilet Association and Hertfordshire Constabulary Crime Prevention Design Service, 2010). As well as improvements to safety, design changes can have benefits for other user needs when done well. For example, removing the door to the facility can also improve access for pushchairs, mobility aids and those with luggage, and remove a point at which germs can be transmitted via the door handle (Knight and Bichard, 2011).

\section{Gender-Neutral Toilets}

Gender-segregated toilets reinforce binary gender identities, where users not only perform the gender of the room they have chosen but their performance is witnessed by others (Cavanagh, 2010; Schweder, 2016). Current guidance allows trans people to use facilities such as gender-segregated toilets that match the gender they identify with and present themselves as (although service providers are allowed to refuse admission on a caseby-case basis). Yet in practice people (transand cis-) can find their gender is misread or questioned by others, and might experience being challenged and removed from gender- 
segregated toilets: 'I get harassed and kicked out and security called, whichever gender toilet I'm using' (Around the Toilet, 2016) or even abused. A survey commissioned by Stonewall found that almost half of trans people (48 per cent) didn't feel comfortable using public toilets due to fear of discrimination or harassment (Stonewall, 2018).

In the USA, the rights of transgender people to access gender-segregated toilets have been the subject of many legal challenges, with some states either passing or considering laws to limit transgender people's access to toilets to those that match their biological sex rather than gender. The Obama administration countered this by instructing federalfunded schools to allow transgender people freedom of choice regardless of sex or gender. This created legal complexities, for example, if a college desegregated all its facilities as a means of protecting trans students, might this simultaneously infringe those same rights of a cis female student who felt sexually vulnerable in this environment (Suk Gersen, 2016). In 2017 these new rules were rescinded by President Trump (Peters et al., 2017).

Likewise, transgender rights have come to the forefront in UK politics. The Gender Recognition Act 2004 gives people who do not identify with their biological sex and associated gender role the opportunity to legally change their gender. However, the current process is viewed by transgender campaigners as part of a diagnosis and treatment process that is informed by medical and psychiatric practice. This process can take many years and requires, amongst other criteria, the medical diagnosis of gender dysphoria. Current proposals to reform the Gender Recognition Act in both Westminster and Holyrood governments seek to make changing gender legally more streamlined and demedicalized (Savage, 2017). The Scottish consultation also proposes to recognize nonbinary people. There are concerns that making gender easier to change (permanently or more fluidly) and strengthening people's rights to access spaces based on gender identity could be open to abuse by violent men to gain access to women-only facilities, which might be considered safe spaces by vulnerable women, such as rape crisis centres, refugees, shelters (BBC News, 2017).

Alongside these proposed changes to how trans people's gender is recognized, there have been calls for more 'gender-neutral toilets' to be more inclusive of those who feel uncomfortable using gender-segregated toilets or who do not identify with either gender. The current draft version of The London Plan (Greater London Authority, 2017a) in point 3.3.1 acknowledges the importance of an inclusive design approach to the capital's built environment, recognizing in this needs relating to both gender and gender expression. In point 5.6.3 it calls specifically for consideration to be given for gender-neutral toilets, although the main point is a call for more separate baby change/family toilets and more ambulant cubicles, both increasing access for those who require more space while reducing demand on the accessible cubicle (Greater London Authority, 2017b).

For many providers who seek to offer gender-neutral provision, a 'quick-fix' solution has been to change the sign on the current 'unisex' accessible provision to include genderneutral. This solution has predominantly emerged in UK universities. Campaigners for disabled access find this solution can compromise the availability of the accessible cubicle, leading to queues for users whose disability and/or medical condition may mean they cannot wait to use the toilet. In addition, such signage may confuse people with cognitive impairments and dementia (Accessibuilt, 2018).

Previous attempts to introduce genderneutral public toilets in the UK can also be considered to have failed. Automatic Public Conveniences (APCs) became a common aspect of the built environment from the 1990s. Classified more as street furniture then buildings they offered provision that was robust against vandalism and self-cleaning. However, they were disliked by many users. 

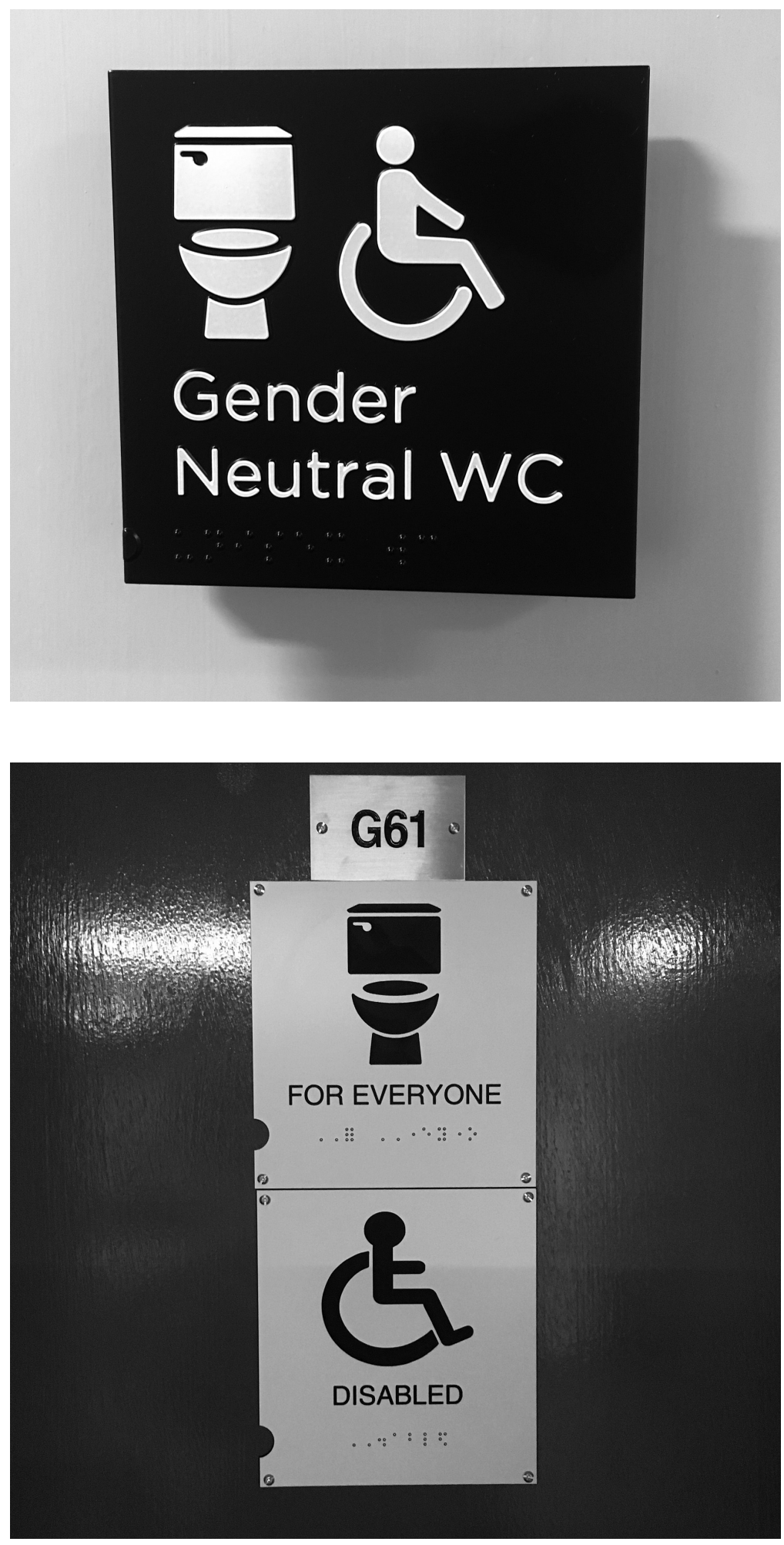

Figures 13 and 14. In some cases gender-neutral toilet provision is being doubled up with accessible toilet provision which may compromise disabled users need to use toilets urgently and guarantee access. (Source: Bichard and Ramster, 2018: 2016) 
In street surveys of 211 people (87 men 124 women) Hanson et al. (2007) found that 71 per cent would not use APCs. A breakdown of this sample by age and gender revealed that no women over the age of 65 would use this form of provision. While this might be due more to the automatic aspect of the provision rather than the gender neutrality of the toilet, it suggests further research should identify whether such provision might be rejected by older people who often require toilets more frequently.

However, there are different ways to include a gender-neutral toilet provision, the design of which can tip the balance of inclusion or exclusion of other user needs. It is not merely a case of changing the signs on the doors. For example, many public toilets and publicly accessible toilets have two separate gendered rooms each with cubicles (and urinals) and shared hand-washing facilities contained within. The cubicles may have solid walls or partitions between them. Theoretically, making such gender-segregated facilities into a gender-neutral offering would have significant benefits for women in terms of queuing (Bovens and Marcoci, 2017). Academics at Ghent modelling various ratios of cubicles to

Figure 15. Gender-neutral automatic public convenience, South Kensington, London. (Source: Bichard and Ramster, 2018)

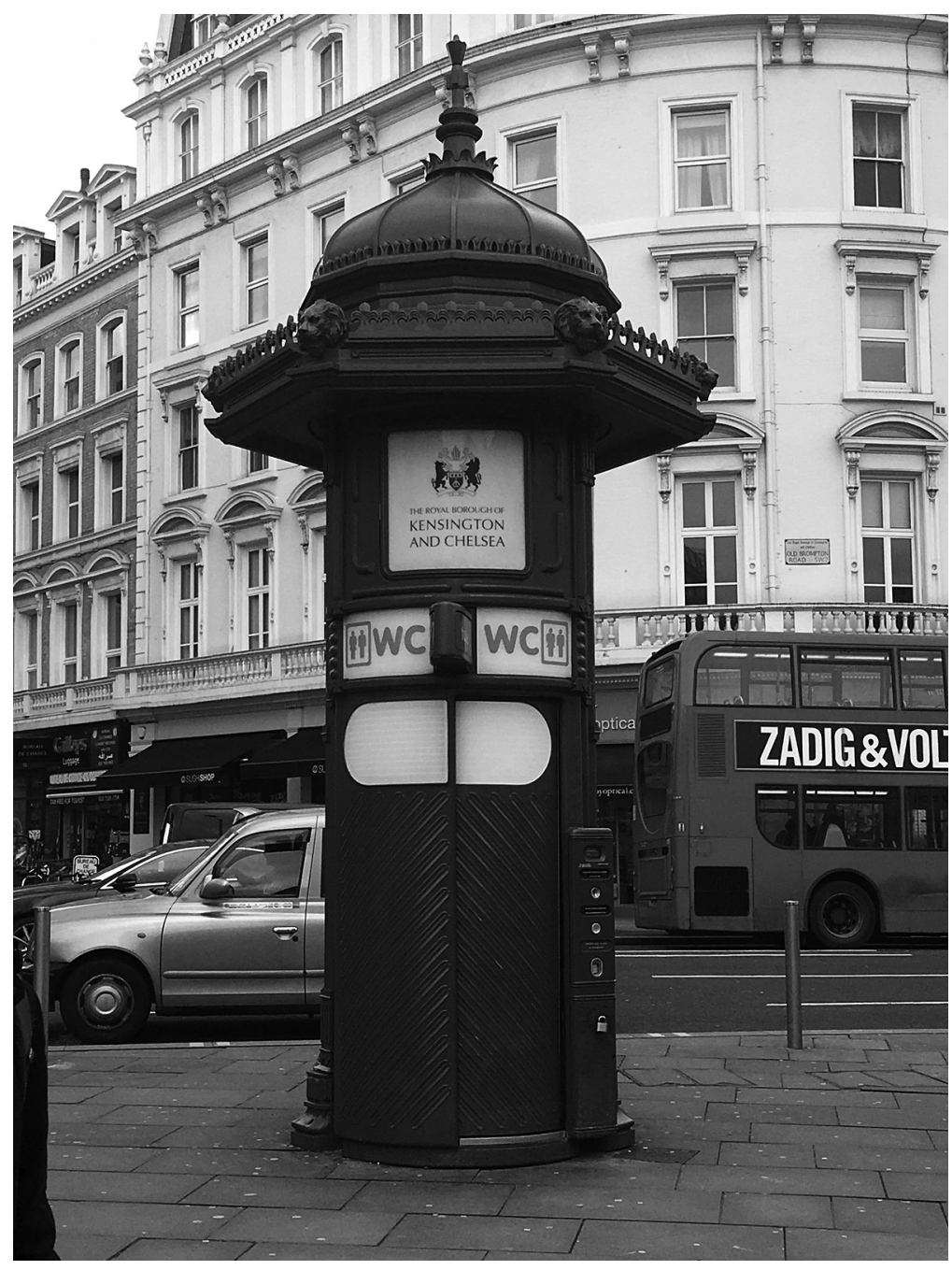


urinals in both separate and gender-neutral facilities found that the best improvement to average wait time (for all users) was in a gender-neutral facility with both cubicles and urinals, observing the ratio of 2 cubicles to 1 urinal (Van Hautegem and Rogiest, 2017). Some feminists are also optimistic that bringing women and men together will actually improve provision for all (Mayer, 2017; Anthony, 2017).

However, the Barbican Centre's experiment with gender-neutral provision led to reports on social media of confusion and frustration amongst some users. They claimed that in practice this further exacerbated the wait time for women as more men than women felt comfortable using both facilities (GraftonGreen, 2017). Indeed, a facility that includes urinals goes against social norms for many UK women (and many men). This scenario where cis- and trans-women are asked to share their facility with others could draw further criticism when considering the likely lack of parity between the level of provision in the two facilities: nowhere are queues more out-of-hand or unequal than at performance spaces where large numbers of people need to use the toilets in a short space of time (preand post-performance; intermissions).

Removing the urinals and replacing them with cubicles within the same footprint is one option. A gender-neutral facility without urinals would still reduce queue length for women and have the advantage of equal wait times for all, though it would have a more significant imposition on wait times

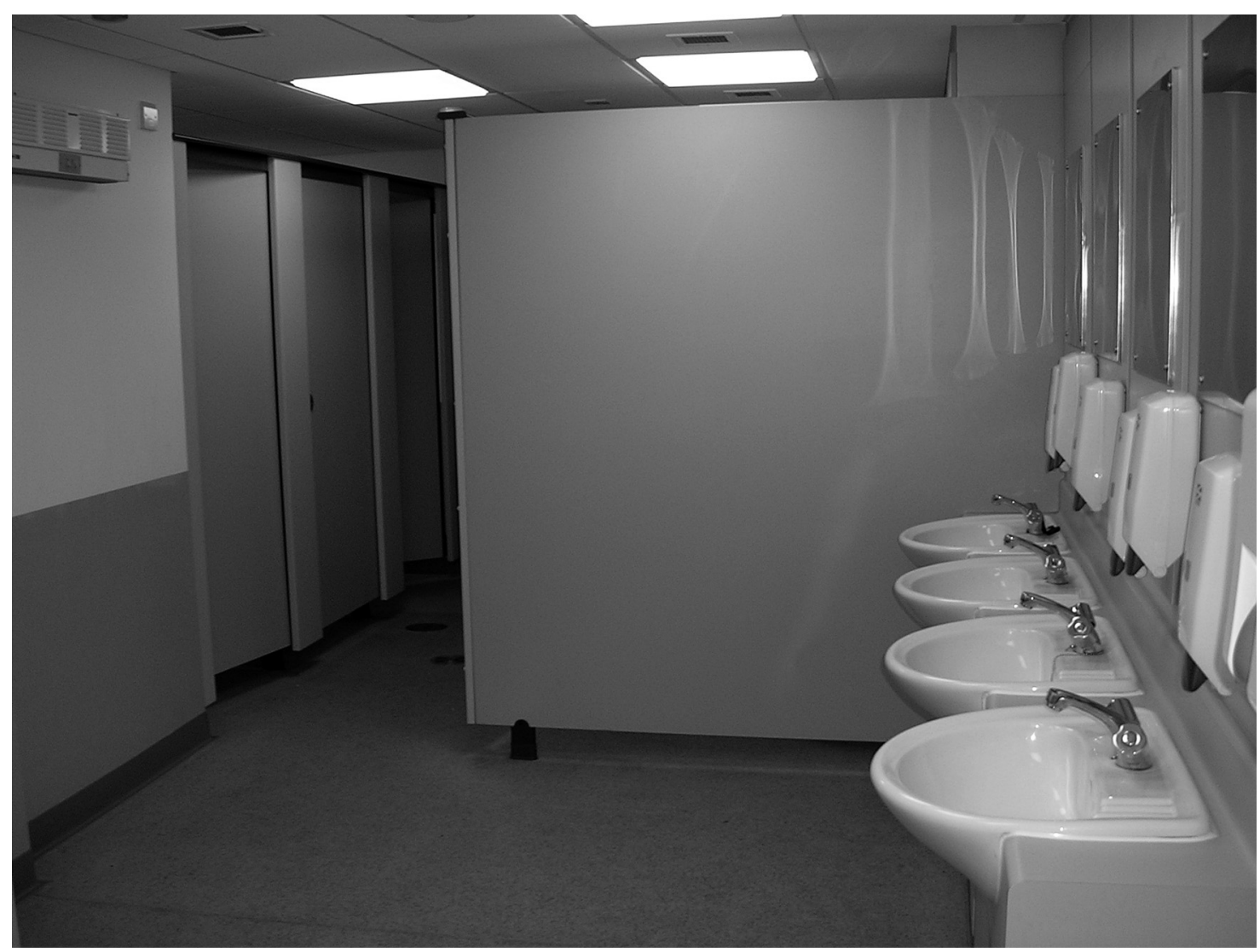

Figure 16. Gendered divided cubicles and washing facilities. (Source: Bichard, 2006) 
for those who could otherwise use urinals (Van Hautegem and Rogiest, 2017). Yet Van Hautegem and Rogiest also demonstrate that significant improvements to women's queue length can also be made within the same architectural space by increasing the size of the women's toilet (by taking space from the men's) to fit 1.5 to 2 times more toilets than the men's facility, retaining gendersegregation.

A loss of privacy goes further than whether urinals (and those using them) are visible to others in a gender-neutral facility. Some women and men simply cannot 'go' in situations where everyone can hear, smell and see everyone else (Soifer, 2001) such as cubicles that have partitions instead of walls. Paruresis is a condition where one struggles to urinate in the presence of others due to the lack of real or perceived privacy, which could affect up to 4 million men and women to an extent where it affects their lives (UK Paruresis Trust, 2018). Privacy can also be a problem for people with complex toileting needs brought about by medical conditions, who may wish to conceal noises, smells or complex selfcare routines, opting instead for the total privacy afforded by an enclosed accessible cubicle. More research is needed to explore how opening up a facility featuring urinals or partitioned cubicles to all genders affects people's ability to use it and how it affects

Figure 17. Enclosed genderneutral cubicles offering more privacy. (Source: Bichard and Knight, 2011)

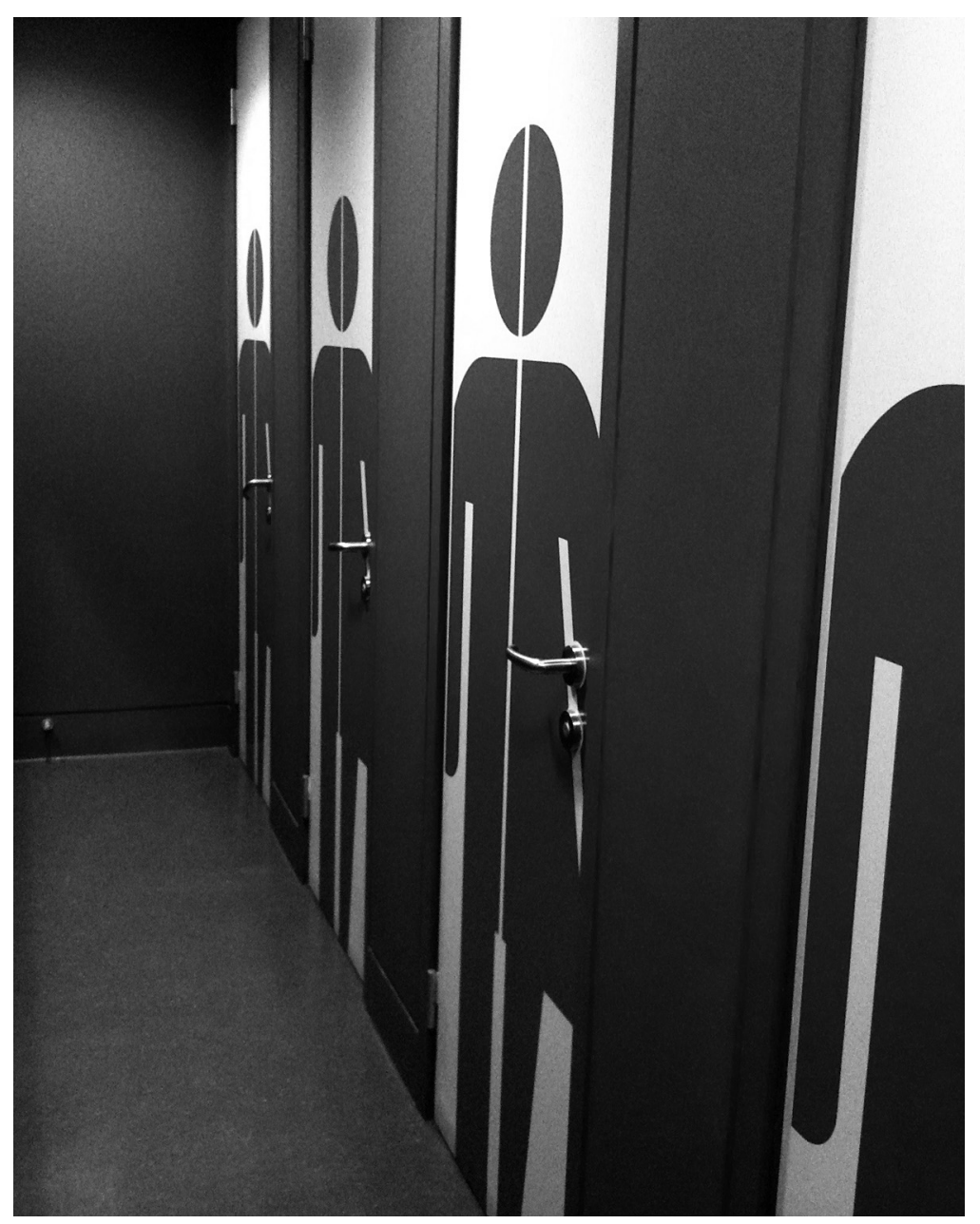


their sense of privacy, comfort and dignity, in particular for people with symptoms of paruresis or managing continence conditions.

While most people are comfortable with the partial privacy of a single-gender facility, the presence of other genders - whether acquaintances or strangers - in a set of partitioned cubicles is outside of the norm beyond primary years. Unlike a private bathroom, a public toilet provides both 'privacyfor' the user to perform bodily functions and 'privacy-from' the user for others in the facility, a form of protection from the actions of strangers (Kira, 1975). Yet different levels of privacy come into play depending on gender. For example, the shared space of the women's toilet provides privacy to adjust dress from men but not from other women. Whether as a consequence of or a reason for gender-segregated facilities, this social norm is unsettled by a gender-neutral facility.

Although this discomfort may be overcome as society evolves, sharing the hand-washing area with other genders could be temporarily disorientating to those used to decades of segregated facilities. People living with dementia have been identified as a group whose needs are not being met due to a lack of consideration in public toilet design, causing confusion and anxiety. This can lead to a reluctance to use facilities, limiting the independent movement important to avoid social isolation (Tales et al., 2017). It can be argued that changing a gender-segregated toilet room to a genderneutral one would be a further exacerbation of poor toilet design for people experiencing cognitive decline, though again further research is required.

Some objections to gender-neutral toilets stem from the loss of a facility regarded by some as women's safe space. Converting segregating blocks to gender-neutral toilet facilities introduces people of all genders into close proximity, where people are undressed, vulnerable and engaged in a private act, a point raised in parliament when Caroline Flint MP asked 'should we not also be wary of creating gender-neutral environments that may prove more of a risk to women themselves? ... How does [Maria Miller MP] think we can protect women from male violence in gender-neutral environments?' (HC Deb o1 December 2016).

Without crime data and analysis it is difficult to say whether a gender-segregated or gender-neutral facility is any more or less of a threat to cis- or trans- women. Maria Miller MP countered that 'we must ensure that people do not use, or perhaps misinterpret, the serious problem of threats to women in environments of that kind to undermine even, perhaps, inadvertently - the rights of transgender people'. However, there is much that could be improved about the environment of some toilet blocks in terms of the vulnerability of users and the atmosphere and natural surveillance of the surroundings, that might improve women's sense of safety and protection, and in turn move the discussion about gender-segregated or gender-neutral facilities away from crime and violence against women.

There are also religious considerations at play. Some faith groups would not use unisex facilities (Olympic Delivery Authority, 2005). For Muslims, ritual washing requiring removal of hijab would be inhibited in a public toilet where the basins were shared and nonsegregated, though for some Muslim women this is already not possible in the women's facility if in the presence of non-Muslim women (BBC, 2009). The Jewish faith also favours modesty in front of all genders including one's own rather than current communal facilities (Broyde and Katz, 2016).

International visitors whose culture is based on more stringent gender-segregated roles may find gender-neutral provision unwelcoming. While the UK may be debating gender-neutral provision, many other countries are seeking gender-segregated provision, having recognized a lack of toilet provision that caters for specific female needs (such as menstruation):

A lack of suitable public and community toilets that meet the requirements and expectations of women and girls impact on many aspects of their 
lives. In most places the inadequacy of both the quality and quantity of toilets for women and girls is related to a historic and ongoing lack of participation of women in the planning and decision-making spheres. (Wateraid, 2017)

In many areas of the world toilets are segregated. Lack of separate facilities for girls and women can restrict their use of the toilet, in both schools and workplaces, particularly in developing countries (Sommer et al., 2016). The United Nations Report on The Human Right to Safe Drinking Water and Sanitation states that gender-specific toilets should be provided, especially in schools, where privacy to deal with menstruation becomes a major factor in determining whether girls attend school or drop out. It requires all public toilet facilities are provided in a manner appropriate to local cultural and religious habits and requirements, with gender segregation being seen as a priority and a basic principle in achieving equality for women, especially in developing countries (De Albuquerque and Roaf, 2012).

An alternative realization of a genderneutral toilet is one where there is no shared space with others away from public space. Mixed-gender direct-access toilets one where the toilet and sink are behind a lockable door with solid walls for complete privacy - are already in daily use by many in the UK in workplaces, trains, planes, and

Figure 18. All-encompassing gender-neutral toilet cubicle that includes washing provision. (Source: Bichard, 2009)

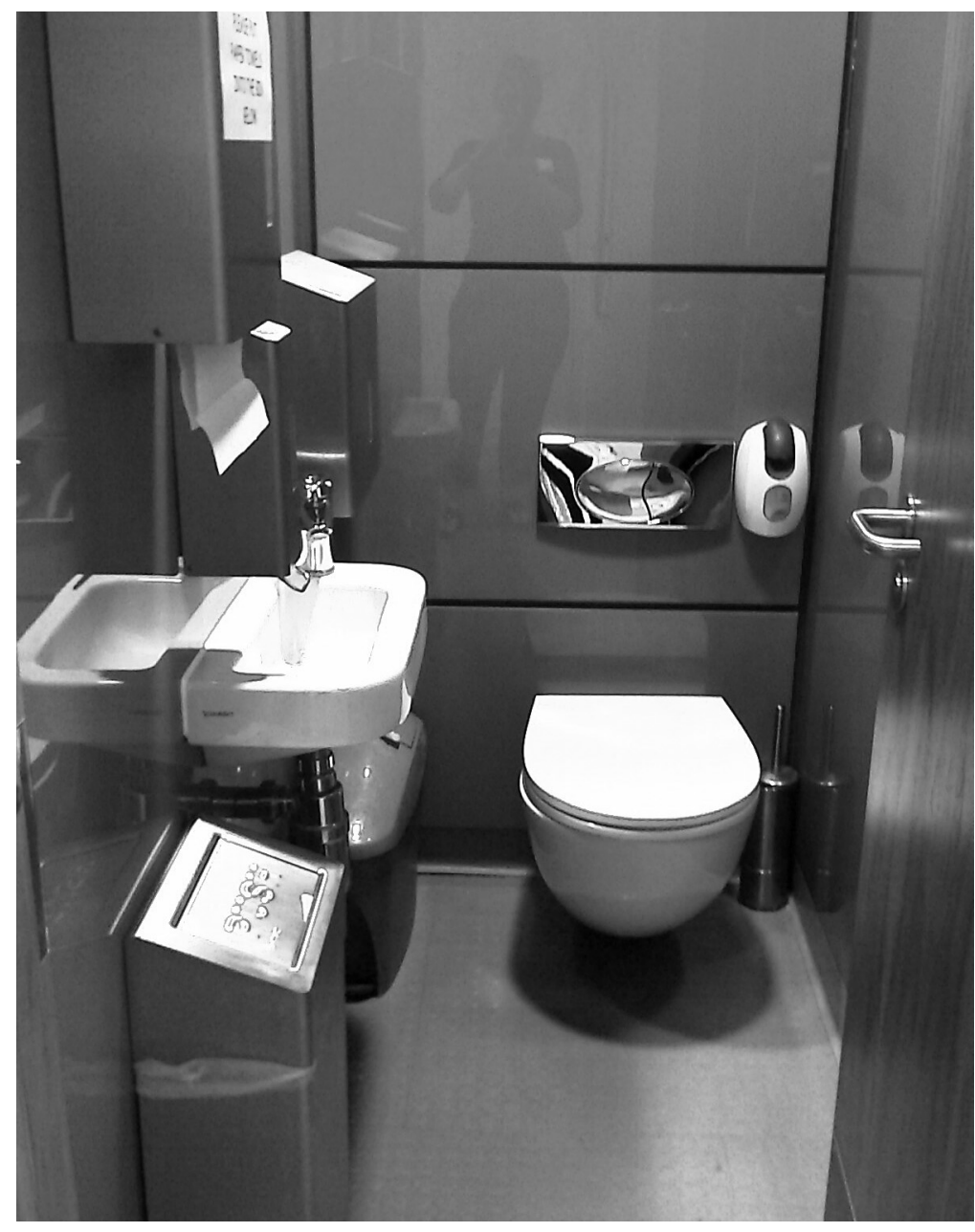


many shops and cafes where only one or two toilets are available.

There are many advantages. They are available to all irrespective of gender and offer parity in queue times. The lack of shared hand-washing and circulation area removes a space where transgender people in particular may be challenged or feel unsafe. They offer complete privacy when using the toilet and also private washing facilities, making them suitable for people with more complex continence needs, such as those managing stomas or catheters, as well as for those managing menstrual hygiene, or who seek privacy for ritual washing, including cleaning with water rather than toilet paper.

Bins and shelves for people managing medical conditions and grab rails for the less mobile could also make direct-access cubicles more inclusive of all, particularly older people, and relieve pressure on the accessible toilet cubicle (Knight and Bichard, 2011).

However, as more user needs are incorporated into the facility, the space requirement of each cubicle increases. This becomes particularly important when people are being assisted by someone, or are responsible for the safety of others, including children and their guardians. If a cubicle is not large enough to fit accompanying children, guardians might still feel comfortable leaving a young child outside a cubicle within a toilet block; less so outside a direct-access cubicle which might open on to indoor or outdoor public space.

A direct-access cubicle in its most basic

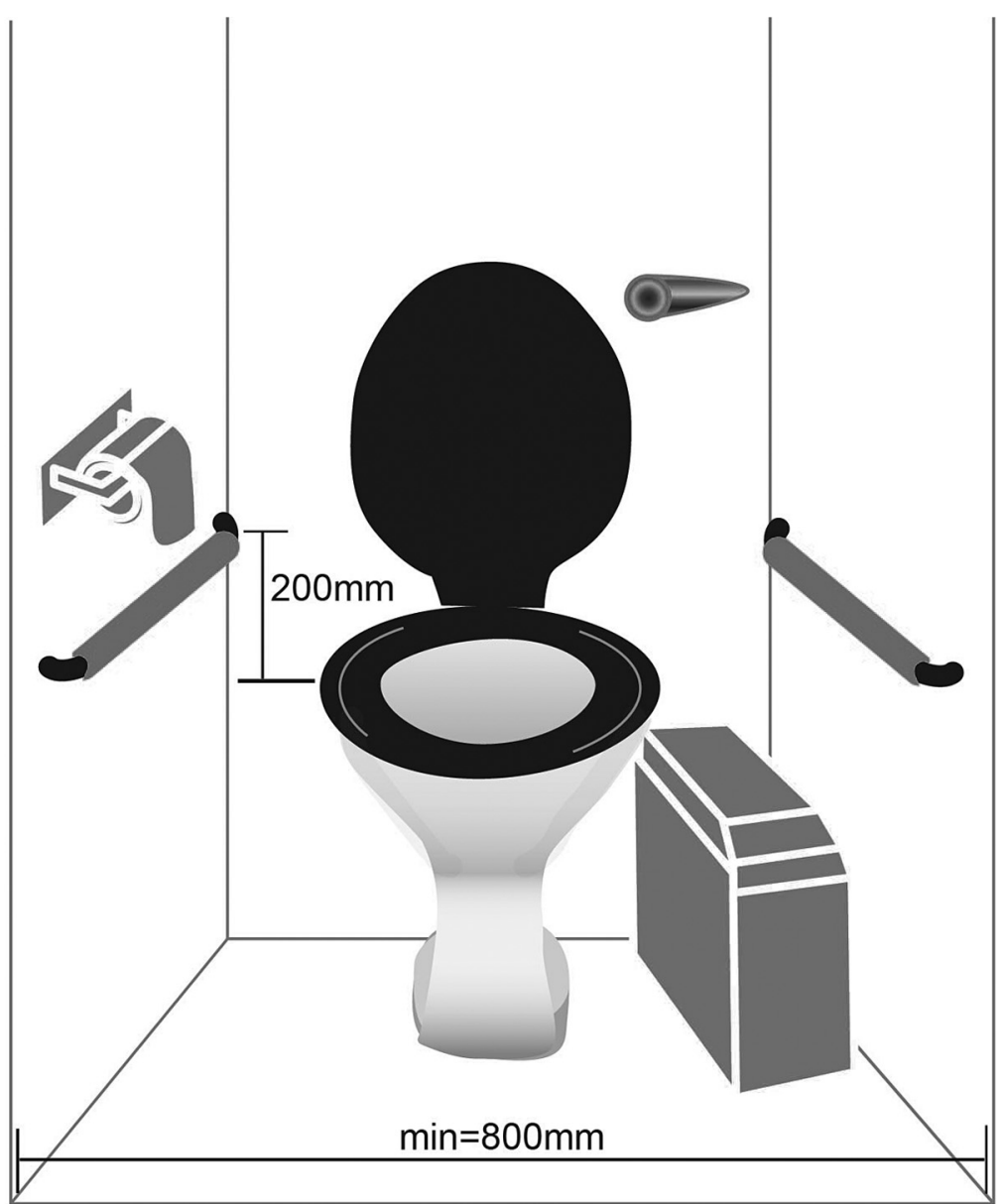

Figure 19. Age friendly cubicle design. (Source: Knight and Bichard, 2011 BUILT ENVIRONMENT VOL 44 NO 1 
form requires more space than a toilet cubicle, and is engaged for longer as washing is now within the cubicle itself. Further research would reveal whether this results in less overall provision within the same footprint of a traditional gender-segregated public toilet (factoring in their latent capacity), and the impact on queueing. It is worth considering that a longer average time in the cubicle cannot be immediately dismissed as a negative but could be a response to a facility that is better meeting people's toileting needs when these require a higher level of privacy.

\section{A Way Forward: Inclusion without Exclusion}

Giving rights to one group, or enforcing those rights, does not mean that rights must be taken away from another group.

(Maria Miller, HC Deb o1 December 2016)

When Maria Miller MP made this statement in the House of Commons it was in the context of the rights of trans people to access toilets under the Equality Act 2010. While allowing people access to gender-segregated toilets based on their gender identity, or doing away with gender-segregated toilets altogether might make some users of gender-segregated toilets uncomfortable, the point at which it infringes on their legal rights is unclear. Further debate is needed to identify the implications of this and how it might impact on the design of the built environment.

As it stands, public toilet design is failing from an inclusive design perspective by not meeting the needs of many users, including those who are transgender. Converting gendersegregated facilities to gender-neutral can seem like an easy win - all genders are included with very little investment beyond the external signage. In some ways, this is a false win for those campaigning for better publicly accessible toilets, as it has done nothing for overall levels of provision: no extra toilets need be built.

However, when seeking to change gender- segregated public toilet provision to genderneutral, consideration must be given to a number of factors that might exclude new and existing users of the facilities, both related and unrelated to gender. These include: the level of privacy afforded to users of cubicles; the appropriateness of gender-neutral facilities with urinals and how users and nonusers might feel excluded from this space; the potential for confusion and anxiety amongst some users of a previously familiar facility; and the current threatening architecture of some public toilet facilities. Some facilities have half-heartedly addressed the issue of urinals by leaving the men's the same and making the women's gender-neutral (Saxby, 2017). Clearly this is unequal and discriminatory provision. If the intention is to replace a gender-segregated toilet room with cubicles with a gender-neutral one, design and architectural changes should be considered to improve the privacy of the facility for all. In cases where direct-access toilets are already in place the conversion could be much more straightforward.

To address the needs of non-binary users (and those who feel excluded or vulnerable in binary gender-segregated space) with an additional, separate, gender-neutral toilet, this provision should be replicated at every facility; for example, proving just one genderneutral toilet in a public building that has several sets of toilet locations could not be deemed equal provision. While this would retain the gendered space of the women's toilet so important for some, it should be recognized and reinforced that this does not remove transgender women's rights to access it.

Further, dividing toilet facilities by gender introduces inefficiency into a system when gender itself is not a reason for design differences - all users regardless of gender require a toilet, hand-washing and privacy, through an enclosed lockable space. Where individual needs exceed these requirements, they can do so for all genders, be it the need to dispose of continence and menstrual products, to clean 
or wash in privacy, for grab rails or space for a wheelchair, to accompany children or be assisted by another. This is already seen in the widespread introduction and use of the unisex accessible cubicle, a facility so popular it has created conflict between groups challenging others as to who has the right to use it (Hanson et al., 2007, Knight and Bichard, 2011; Bichard, 2015, Crohn's and Colitis UK, 2018).

Designing to meet the needs of users rather than their gender would lead to a more inclusive toilet provision. Currently genderneutral toilets risk excluding rather than including in situations where a significant user need is already falling short: the need for privacy. In this most personal and private interaction with our built environment, most public toilets do not provide privacy from strangers of one's own gender, due to partition walls, a lack of audio privacy, and shared handwash spaces. Therefore, the design of the space is starting from an ineffective position. While many (though not all) users are either comfortable, or have come to accept, sharing with others of the same gender as a cultural norm, gender-neutral provision disrupts this, creating discomfort and new routes to exclusion.

Advances in toilet provision in the United States has resulted in progressive moves towards provision including potty parity and gender-neutral toilets. However, this is difficult to translate directly to a UK footprint due to the sheer difference in the size of territories. Hence architects, designers and planners need to consider a specific UK mode of provision that takes into account existing stock and new builds that meet (and hopefully exceed) inclusive design guidance.

Through gender-neutral direct-access toilets, privacy is restored. The extra capacity gained by more efficient non-gendered through flow of users could be exchanged for larger cubicles, particularly those that address otherwise excluded user groups: ambulant toilets; accessible toilets, family toilets, and Changing Places toilets. To be appropriate for an inclusive society, public and publicly accessible toilet design might focus on user needs instead of gender, and restore privacy from all, for all.

\section{REFERENCES}

Accessibuilt (2018) Question on proposed signage (Online forum comments) Messages posted to: https://www.jiscmail.ac.uk/cgi-bin/ webadmin?A0=ACCESSIBUILT.

Anthony, K. (2017) Defined by Design: The Surprising Power of Hidden Gender, Age and Body Bias in Everyday Products and Places. New York: Prometheus Books.

Armstrong, L. and Scott, A. (1992) Whitewash: Exposing the Health and Environmental Dangers of Women's Sanitary Products and Disposable Diapers. Toronto: HarperPerrenial.

Around the Toilet (2016) Toilet Tales (video). Available at: https://www.youtube.com/ watch?v=vbPVE68IS_s.

Baillie, M., Fraser, S. and Brown, M. (2009) Do women spend more time in the restroom than men? Psychological Reports, 105(3), pp. 789-790.

BBC News (2002) How public toilets became an inconvenience. Available at: http://news.bbc. co.uk/1/hi/uk/2191727.stm.

BBC (2009) Islam: Hijab. BBC Religions. Available at: http://www.bbc.co.uk/religion/religions/ islam/beliefs/hijab_1.shtml/

BBC News (2016) Public toilets 'wiped out in parts of UK'. Available at: http://www.bbc.co.uk/ news/uk-36405414.

BBC News (2017) Do trans rights affect women's rights? Available at: http://www.bbc.co.uk/ news/uk-40713645.

Bichard, J. (2010) Case Study Report London (Clerkenwell). The Inclusive Design of Away from Home (Public) Toilets or Away from Home Toilet Provision in Clerkenwell. Available at: http://www.vivacity2020.co.uk/ publications/index.html\#sustainability-issueseven-public.

Bichard, J. (2015) Extending Archestecrtural Affordance: The Case of the Publicly Accessible Toilet. PhD Thesis, University College London. Available at: http://discovery.ucl.ac.uk/1467131/ 2/Bichard\%202014\%20Res.pdf.

Bichard, J., Hanson, J. and Greed, C. (2004) Access to the Built Environment - Barriers, Chains and Missing Links: Review. London: University College London. 
Bovens, L. and Marcoci, A. (2017) To those who oppose gender-neutral toilets: they're better for everybody. The Guardian, 1 December. Available at: https://www.theguardian.com/ commentisfree/2017/dec/01/gender-neutraltoilets-better-everybody-rage-latrine-transdisabled.

British Toilet Association and Hertfordshire Constabulary Crime Prevention Design Service (2010). Publicly Available Toilets: Problem Reduction Guide. Bangor, Co. Down: BTA. Available at: http://www.btaloos.co.uk/wp-content/uploads /2014/01PubliclyAvailableToiletsProblemRedu ctionGuide.pdf.

Broyde, M. J and Katz, A.D. (2016) A Jewish solution on transgender bathrooms. The New York Jewish Week. Available at: http://jewish week.timesofisrael.com/a-jewish-solution-ontransgender-bathrooms/.

BSI (British Standards Institution) (2017) BS 64652: Sanitary Installations. Space Recommendations. Code of Practice. Milton Keynes: BSI

Case, M. (2010) Why not abolish laws of urinary segregation? in: Molotch, H. and Noren, L. (eds.) Toilet: Public Restrooms and the Politics of Sharing. New York: New York University Press.

Catalyst (2016) Women in the Workforce UK. Available at: http://www.catalyst.org/ knowledge/women-workforce-uk.

Cavanagh, S. (2010) Queering Bathrooms: Gender Sexuality and the Hygienic Imagination. Toronto: University of Toronto Press.

Cavanagh, S. and Ware, V. (1990) At Women's Convenience: A Handbook on the Design of Women's Public Toilets. London: Women's Design Service.

Chrisler, J., Gorman, J., Manion, J., Murgo, M., Barney, A., Adams-Clark, A., Newton, J. and McGrath, M. (2016). Queer periods: attitudes toward and experiences with menstruation in the masculine of centre and transgender community. Culture, Health $\mathcal{E}$ Sexuality, 18(11), pp. 1238-1250.

CLG (Communities and Local Government Committee) (2008) The Provision of Public Toilets. 12th report of session 2007-8. HC736. London: The Stationery Office, London. Available at: https://publications.parliament.uk/pa/ cm200708/cmselect/cmcomloc/636/63602.htm.

Couvée, K. (2017) We won't stand for Barbican gender-neutral loos, say women. Islington Tribune. Available at: http://islingtontribune. com/article/we-wont-stand-for-barbicangender-neutral-loos-say-women.
Crohn's and Colitis UK (2018) Accessible Toilet Signs: Not Every Disability is Visible. St Albans: Crohn's and Colitis UK. Available at: https:// www.crohnsandcolitis.org.uk/get-involved/ campaigning/accessible-toilet-signs.

De Albuquerque, C. and Roaf, V. (2012) On the Right Track: Good Practices in Realising the Rights to Water and Sanitation. Paris: UNESCO WWAP.

Don, G.G. (1961) Public conveniences in the London area: a survey and some recommendations. The Medical Officer, 8 December.

Gershenson, O. and Penner, B. (eds.) (2009) Ladies and Gents: Public Toilets and Gender. Philadelphia, PA: Temple University Press.

Goldsmith, S. (1963 [1997[) Designing for the Disabled. London: Routledge.

Grafton-Green, P. (2017) Barbican to review gender-neutral toilets after furious row. Evening Standard, 6 April. Available at: http:// www.standard.co.uk/news/london/barbican-toreview-genderneutral-toilets-after-furious-rowover-long-queues-for-women-a3509136.html,

Greater London Authority (2017a) Policy D3 Inclusive Design, in Draft New London Plan. Available at: https://www.london.gov.uk/whatwe-do/planning/london-plan/new-londonplan/draft-new-london-plan/chapter-3-design/ policy-d3-inclusive-design.

Greater London Authority (2017b) Policy S6 Public toilets, in Draft New London Plan. Available at: https://www.london.gov.uk/what-we-do/plan ning/london-plan/new-london-plan/draft-newlondon-plan/chapter-5-social-infrastructure/ policy-s6-public-toilets.

Greed, C. (2003) Inclusive Urban Design: Public Toilets. Oxford: Architectural Press.

Greed, C. (2009) The role of the public toilet in civic life, in Gershenson, O. and Penner, B. Ladies and Gents: Public Toilets and Gender. Philadelphia: Temple University Press.

Greed, C. (2012) Planning and transport for the sustainable city or planning for people. Journal of Urban Design and Planning, 165(DP4), pp. 219-229.

Greed, C. (2016) Taking women's bodily functions into account in urban planning policy: public toilets and menstruation. Town Planning Review, 87(5), pp. 505-523.

Hanson, J., Bichard, J. and Greed, C. (2007) The Accessible Toilet Resource Manual. London: University College London. Available atL http://discovery.ucl.ac.uk/4847/.

House of Commons Debate (01 December 2016) 
Vol. 617, col. 1694. Available at: https://hansard. parliament.uk/Commons/2016-12-01/debates/ D4F283FB-2C02-4C8C-8C7E-BEAB889D1425/ TransgenderEquality.

Help the Aged (2007) Nowhere to Go: Public toilet provision in the UK. London: Help the Aged, pp. 5-6. Available at: https://www.ageuk.org.uk/ documents/en-gb/for-professionals/research/ nowhere $\% 20$ to $\% 20$ go $\% 20$ public $\% 20$ toilet $\% 20$ provision\%20(2007)_pro.pdf?dtrk=true=.

Kira, A (1975) The Bathroom. Harmondsworth: Penguin.

Knight, G. (2010) Public Toilets and ... Crime. Available at: https://gailknight.wordpress. com/2010/11/29/crime/.

Knight, G. (2016) Public Toilets and ... a $28 \%$ reduction in loos since 2000. Available at: https://gailknight.wordpress.com/2016/04/26/a28-reduction-in-loos-since-2000/.

Knight, G. and Bichard, J. (2011) Publicly Accessible Toilets: An Inclusive Design Guide. London: Helen Hamlyn Centre for Design. Available at: https://www.brunel.ac.uk/_data/assets/pdf file/0004/148792/Publicly-Accessible-Toilets.pdf.

Lees, P. (2017) There's nothing to fear from gender neutral toilets - the Barbican is just doing them badly. The Telegraph, 6 April. Available at: http://www.telegraph.co.uk/news/2017/04/06/ nothing-fear-gender-neutral-toilets-barbicanjust-badly/.

London Local Authorities Act 2012. Available at: http://www.legislation.gov.uk/ukla/2012/2/ contents/enacted.

McCabe, S. (2012) The Provision of Underground Public Conveniences in London with Reference to Gender Differentials. MA Dissertation. Institute of Historical Research, London. Available at: http://sas-space.sas.ac.uk/6093/1/ MA\%20Dissertation\%20Sarah\%20McCabe\%20 September\%202012.pdf.

Mayer, C. (2017) Attack of the $50 \mathrm{ft}$ Women: How Gender Equality Can Save the World. London: Harper Collins.

Miyanishi, Y. (1996) Comfortable Public Toilets: Design and Maintenance Manual. Toyama: City Planning Department.

Mulvey, L. (1975) Visual pleasure and narrative cinema. Screen, 16(3), pp. 6-18.

ONS (Office of National Statistics) (2016) Overview of the UK Population. Available at: https://www. ons.gov.uk/peoplepopulationandcommunity/ populationandmigration/populationestimates/ articles/overviewoftheukpopulation/february 2016.
Olympic Delivery Authority (2005) Inclusive Design Standards. London: ODA. Available at: http:// learninglegacy.independent.gov.uk/documents/ pdfs/equality-inclusion-employment-andskills/62-inclusive-design-standards-eies.pdf.

Penner, B. (2001) A world of unmentionable suffering: women's public conveniences in Victorian London. Journal of Design History, 14(1), pp. 35-52.

Penner, B. (2005) Researching female public toilets: gendered spaces, disciplinary limits. Journal of International Women's Studies, 6(2), pp. 81-98.

Penner, B (2013) Bathroom. London: Reaktion Books.

Periodwatch (2018) Countdown to the axe of the tampon tax. Available at: https://www. periodwatch.org/period-blog.

Peters, J., Becker, J. and Hirschfeld Davis, J. (2017) Trump rescinds rules on bathrooms for transgender students. New York Times, 22 February. Available at: https://www.nytimes. com/2017/02/22/us/politics/devos-sessionstransgender-students-rights.html.

Public Health Act 193626 Geo 5 and 1 Edw 8, c.49. London. Her Majesty's Stationery Office.

Public Lavatories (Turnstiles) Act 1963. Available at: https://www.legislation.gov.uk/ukpga/1963/32.

Rothburn, M. and Dunnigan, M. (eds.) (2004) The Infection Control, Prevention and Control of Infection Policy. Liverpool: National Health Service Trust Hospitals, Mersey Manual.

Sanghani, R. (2017) Why the UK should ditch male and female toilets for 'gender-neutral' loos? The Telegraph, 6 April. Available at: http:// www.telegraph.co.uk/women/life/why-theuk-should-ditch-male-and-female-toilets-forgender-neutr/.

Savage, M. (2017) Gender reassignment could be streamlined under proposal. The Guardian, 23 July. Available at: https://www.theguardian. com/world/2017/jul/23/gender-reassignmentcould-be-streamlined-under-proposal.

Saxby, H. (2017) The thing about toilets. Not the News in Briefs, 26 November. Available at: https://notthenewsinbriefs.wordpress. com/2017/04/11/the-thing-about-toilets/.

Schweder, A. (2016) A piss-poor performance. Dirty Furniture, No. 3/6, pp. 99-109. Available at: http://www.alexschweder.com/wp-content/ uploads/2017/03/Dirty-Furniture.pdf.

Sex Discrimination (Amendment of Legislation) Regulations 2008 (No.963). regs.3 London: HMSO. 
Sinmaz, E. and Strick, K. (2017) Barbican Centre ditches male and female toilets for 'genderneutral'. Mail Online. Available at: http://www. dailymail.co.uk/news/article-4385984/FuryBarbican-Centre-ditches-male-female-toilets. html.

Soifer, S. (2001) Shy Bladder Syndrome. Oakland, CA: New Harbinger Pub.Sommers, M., Chandraratna, S., Mahon, T. and Phillips-Howard, P. (2016) Managing menstruation in the workplace: an overlooked issue in low- and middleincome countries. International Journal for Equity in Health, 15, Available at: https://equityhealthj. biomedcentral.com/articles/10.1186/s12939-0160379-8.

Stanwell-Smith, R. (2010) Public toilets down the drain? Why privies are a public health concern. Public Health, 124(11), pp. 613-616.

Stonewall (2018) New Research Exposes Profound Discrimination Trans People Face. Available at: https://www.stonewall.org.uk/news/newresearch-exposes-profound-discriminationtrans-people-face [Accessed 12 Feb. 2018].

Street-Porter, J. (2016) Closing public loos is one austerity cut too many. The Independent, 3 June. Available at: http://www.independent.co.uk/ voices/closing-public-toilets-human-rightausterity-cuts-a7063346.html.
Suk Gersen, J. (2016) The transgender bathroom debate and the looming title IX crisis. The New Yorker, 24 May. Available at: https://www.new yorker.com/news/news-desk/public-bathroomregulations-could-create-a-title-ix-crisis.

Tales, A., Burholt, V., Nash, P., Bichard, J. and Clayton-Turner, A. (2017) Dementia-friendly public toilets. The Lancet, 390, pp. 552-553.

Time Out Film (2017) Here's What the Barbican is Saying about Its Gender Neutral Toilets. Time Out London. Available at: https://www.timeout. $\mathrm{com} / \mathrm{london} / \mathrm{blog} /$ heres-what-the-barbican-issaying-about-its-gender-neutral-toilets-040717.

UK Paruresis Trust (2018) Spectrum of Severity. Kendal: UK Paruresis Trust. Available at: https://www.ukpt.org.uk/coping-with-ap/ spectrum-of-severity.

Van Hautegem, K. and Rogiest, W. (2017) No more queueing at the ladies' room. People Queue Magazine. Available at: http://peopleqm. blogspot.co.uk/2017/07/no-more-queueing-atladies-room.html.

Wateraid (2017) Request for Proposal - FemaleFriendly Toilets. Available at: https://www. wateraid.org/request-for-proposals-femalefriendly-toilets.

WEN (Women's Environmental Network) (2012) Seeing Red: Sanitary Protection and the Environment. London: WEN.) 